Portland State University

PDXScholar

1978

\title{
A survey of reading-readiness skills and their application to the late reader
}

\section{Gail E. Robbins}

Portland State University

Follow this and additional works at: https://pdxscholar.library.pdx.edu/open_access_etds

Part of the Education Commons, and the School Psychology Commons Let us know how access to this document benefits you.

\section{Recommended Citation}

Robbins, Gail E., "A survey of reading-readiness skills and their application to the late reader" (1978). Dissertations and Theses. Paper 2842.

https://doi.org/10.15760/etd.2836

This Thesis is brought to you for free and open access. It has been accepted for inclusion in Dissertations and Theses by an authorized administrator of PDXScholar. Please contact us if we can make this document more accessible: pdxscholar@pdx.edu. 
AN ABSTRACT OF THE THESIS OF Gail E. RObbins for the Master of Science in Education presented July 28, 1978.

Title: A Survey of Reading-Readiness Skills and Their Application to the Late Reader.

APPROVED BY MEMBERS OF THE THESIS COMMITTEE:

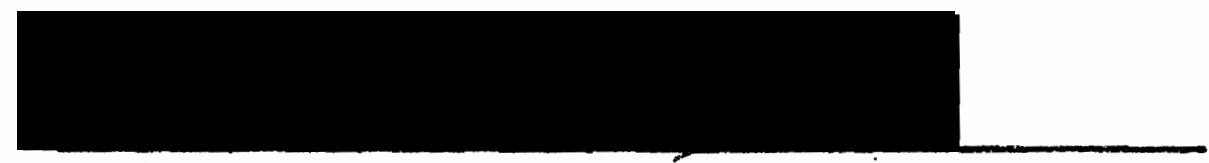

Colin Dunkeld, Chairman

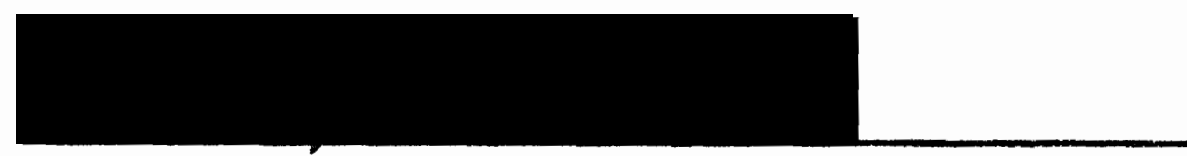

Ulrich $\mathrm{H}$. Hardt

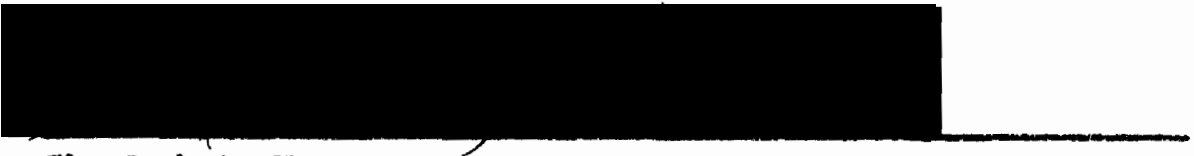

Chadwick Karr

Reading readiness is a subject that concerns reading teachers and educators. Inadequate readiness training may cause some students to become late readers, who can be identified as students who score below their age and grade level on a standardized reading test. It is important to define reading readiness and examine the component skil1s and factors in order to help late readers. This examination 
was conducted by a study of reading-readiness literature. The reading-readiness skills include auditory discrimination, visual and visual-motor discrimination, development of language, concept formation, and reasoning skills. Readiness factors include fixed factors, social, and emotional factors. Fixed factors cannot be changed or improved by instruction, such as age, sex, I.Q., and physical health. Social and emotional factors can often be improved by manipulating the classroom environment and providing nurturing experiences.

Reading readiness was defined as a developmental process composed of skills and factors, most of which can be taught. It is an on-going process which should serve as an introduction to the development of reading skills at all levels of the reading acquisition process.

In considering the importance of reading in society, a brief examination was made of the statistics of reading failure and the causes of reading failure. It was found that approximately $13 \%$ of students nearing the end of high school are unable to read basic, everyday reading material. Some of the causes of this failure are developmental and educational inadequacies.

It will always be true that some students will not learn the reading skills during the initial period of instruction. These late readers present an educational problem to the teacher and society. In order to assist the teacher in planning an instructional program to meet the 
needs of late readers, reading-readiness tests were examined and a tentative skills sequence was developed. For the purpose of assessing reading readiness, four standardized tests were examined and compared to the component skills and factors of reading readiness. A tentative reading-readiness skills sequence was developed from studying readiness skills, the reading acquisition process, readiness tests, learning hierarchies, and my professional experience as a reading teacher. The skills sequence is a guideline for teachers to use when planning a program for late readers. It suggests that that when a student is having difficulty mastering a skill, an earlier skill has not been mastered. By referring to the skills sequence, a teacher can locate the skill weakness, as defined by observation and a readingreadiness test, then teach and check the skills along the sequence.

Helping late readers overcome their reading weakness becomes a three-step process: understanding the component skills and factors of reading readiness, knowing how to identify reading weaknesses, and using a tentative skills sequence to develop an instructional program. Knowledge of these three aspects of reading readiness will help teachers plan a reading program that is logical and manageable. 
A SURVEY OF READING-READINESS SKIIIS AND THEIR APPLICATION TO THE IATE READER

\author{
by \\ GAII E. ROBBINS
}

A thesis submitted in partial fulfillment of the requirements for the degree of

MASTER OF SCIENCE

in

EDUCATION

Portland State University

1978 
TO THE OPFICE OF GRADUATE STUDIES AND RESEARCH:

The members of the Committee approve the thesis of Gail I. Robbins presented July 28, 1978.
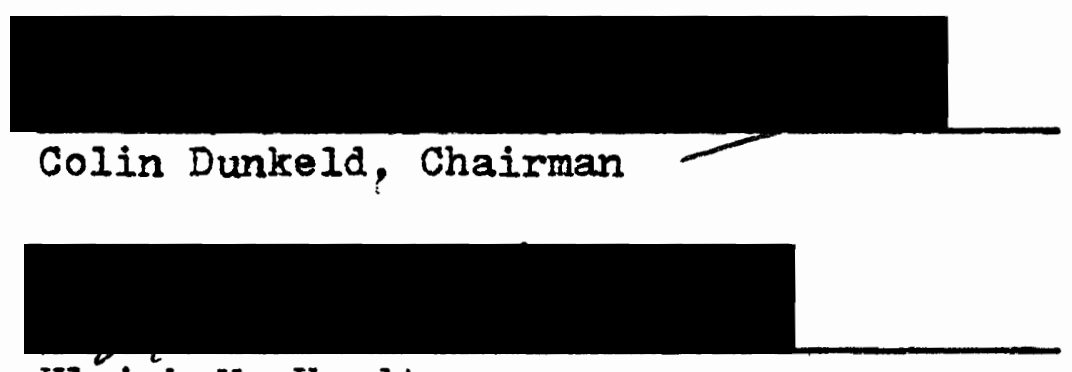

$$
\text { Ulrich H. Hardt }
$$

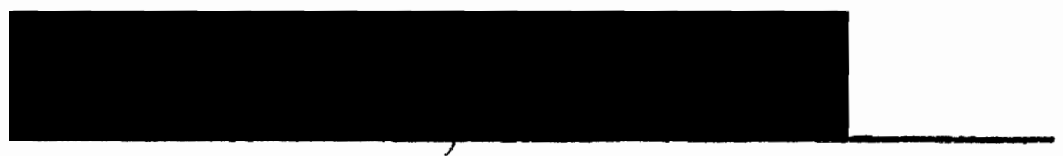

Chadwick Karr

APPROVED :

Dean, School be Education

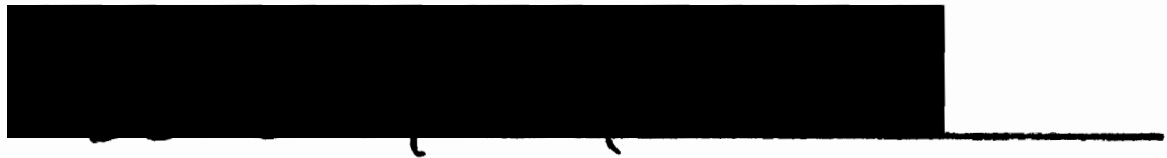

Dean, Graduate Studies and Research 


\section{PREFACE}

The major purpose of this study is to examine reading-readiness skills, to examine several tests of reading readiness, and to develop a tentative sequence of skills to assist in planning an instructional program for late readers. To achieve this purpose, a review of the literature on reading readiness has been undertaken to define reading readiness and the skills and factors involved. Reading readiness is a developmental process composed of skills and factors, most of which can be taught. The reading-readiness skills include auditory discrimination, visual and visualmotor discrimination, development of language, concept formation, and reasoning skills. Readiness factors include fixed factors, which cannot be changed or improved by instruction, such as age, sex, I.Q., and physical health. Social and emotional factors can often be improved by manipulating the classroom environment and providing nurturing experiences.

In considering the importance of reading in society, a brief examination is made of the statistics of reading failure and the causes of reading failure. A study conducted by the National As sessment of Educational Progress found that about $13 \%$ or approximately one out of ten students nearing the end of high school is unable to read basic, everyday material. The causes of reading failure are divided 
into two groups: developmental and educational. The developmental causes result from inadequate physical, emotional, and mental maturity. The educational causes result from inadequate readiness training which often neglects the importance of direct skill instruction. Inadequate instruction may result from poor teacher expertise, such as relying on basal readers exclusively or teaching only one reading method to all students.

For the purpose of assessing reading readiness, an examination of four commercially-published reading-readiness tests is undertaken. These tests were selected on the basis of their overall acceptibility by reading authorities as well as their inclusion of the readiness skills examined in Chapter II. The tests examined are the Gates-MacGinitio Reading Skills Test, the Metropolitan Readiness Test, The Clymer-Barrett Prereading Battery and the Murphy-Durreil Reading Readiness Analysis. Information from these kinds of tests can be used to supplement informal testing and teacher observation to determine a student's readiness to learn to read. Reading-readiness tests can be used to identify late readers, provide diagnostic information about specific prereading skills and abilities, as well as provide instructional implications for grouping students.

A tentative reading-readiness skills sequence has been developed for the purpose of applying the data from the reading-readiness tests within an instructional program that 
is logical and built upon the theory that readiness skills are sequential. They follow a developmental order where earlier skills are components of later skills. Although the complexity of the reading process has defied the establishment of a proven reading skills hierarchy, there is empirical evidence to support a sequence of decoding and comprehension skills. The tentative reading-readiness skills sequence was developed to assist teachers in planning an instructional program for late readers. Late readers are defined as students who do not learn the skill being taught during the initial instruction period and consequently score below their age and grade level on a standardized reading test. Using a hierarchical theory, the assumption is that when a student is having difficulty mastering a skill, an earlier skill has not been mastered. By referring to the skills sequence, a teacher can locate the skill weakness, then teach and check the skills along the sequence. The final step in planning an instructional program is to select a method or combination of methods that is appropriate to the student's age and reading weakness. 


\section{ACKNOWLEDGMENTS}

I would like to thank the members of my thesis committee for their assistance and valuable suggestions. Dr. Karr was particularly helpful with the section dealing with interpreting and evaluating readiness tests. Dr. Hardt was meticulous in making helpful stylistic comments. Dr. Dunkeld was a most concerned advisor, giving attention and specific suggestions to insure a well-researched paper.

I would also like to thank my husband, Rick, for his understanding and encouragement during the past three years of my graduate study. 
TABLE OF CONTENTS

PAGE

PREFACE • • • • • • . . . . . . . . . •

ACKNOWLEDGMENTS . . . . . . . . . . . . . . vi

IIST OF TABLES . . . . . . . . . . . . . ix

CHAPTER

I INTRODUCTION •. •. . . . . . . . 1

II REVIEW OF THE IITERATURE . . . . . . . 4

Definition of Reading Readiness . . . 4

Reading-Readiness Skills . . . . . ?

Auditory

Visual, visual-motor

Language

Concept Formation

Reasoning

Reading-Readiness Factors . . . . 15

III DESCRIPTION OF THE PROBLEM . . . . . 25

Statistics on Reading Disability . . 2 ?

Causes Contributing to Reading

Failure . . . . . . . . 28

Developmental

Educational

IV IDENTIPYING READING-READINESS SKILIS • •

Why Reading-Readiness Tests are

Given . . . . . . . . . .

Choosing A Reading-Readiness

Test 
An Examination of Selected

Reading-Readiness Tests . . . .

Gates-MacGinitie

Netropolitan

Clymer-Barrett

Murphy-Durrell

$V$ APPIYING THE DATA FROM READING-READIINESS TESTS . . . . . . . . . . . .

A Reading-Readiness Skills

Sequence

Using the Sirilis Sequence for

the Late Reader.........

Placement on the Sequence of Skills Hierarchy ......

VI CONCLUSIONS . . . . . . . . . . . 


\section{LIST OF TABLES}

I A Tentative Reading-Readiness Skills

Sequence . . . . . . . . .

II Skills Included in Four Reading-Readiness

Tests and Their Location on the

Reading-Readiness Skills Sequence . . 


\section{CHAPTER I}

\section{INTRODUCTION}

There is considerable evidence to support the conclusion that students' success in learning to read is determined by their degree of "readiness." Readiness is no longer considered strictly a developmental process which comes about regardless of training. Reading readiness is acquired by students in varying degrees and can be taught to those who lack readiness skills. The best way to test reading readiness is to test abilities and these abilities can be learned (Gates, 1939).

Essentially, reading readiness testing is the same as testing reading attainments at any later time from the second grade to college. That is, there are skills and abilities which are prerequisite to learning to read, and a readiness test is an expression of an individual's attainment of those important abilities. The problem then is to define reading readiness and identify the factors and skills which are prerequisite to begin reading.

Iike any learning and growing phenomenon, reading is a sequential process. Based on an examination of the research, the reading readiness skills will be arranged in a tentative sequential order within skill areas. The purpose 
of the reading-readiness skills sequence is to provide teachers with a guideline to use when planning an instructional program. The sequence suggests that mastery of one skill will facilitate mastery of the next skill in the sequence.

Despite the careful application of reading-readiness training, it will always be true that some students will not acquire the essential skills during the initial period of instruction. There may be one or many factors causing the lack of learning at this time. An analysis of these factors, together with data on specific skills which are deficient, will help in planning a readiness program to meet the individual needs of the student.

Although reading readiness is a term which has traditionally been associated with very young children, the extent readiness skilis apply to anyone who learns to read, renders the age factor negligible. While the reading-readiness skills and factors examined are appropriate for kindergarten and first-grade learners, the emphasis in the following pages is that these skills are identical for the late reader--that is, the student who has not acquired these skills during the initial instruction period. This is intended to designate students who score below their age and grade level on a standardized reading test and to suggest that the reason may lie in failure to master readingreadiness skills. 
It is possible to determine which reading-readiness skills have not been acquired by a student, regardless of age. For this purpose, several commercially-published reading-readiness tests will be examined and compared to the tentative sequence of skills considered to be prerequisite of beginning formal reading. Once a student's reading-readiness skills have been measured, the point of attainment and point of deficiency should identify a place on the sequence of skills. This defines the point at which instruction should begin. Once this point has been identified, the sequence of skills may assist the teacher in planning an instructional program that is logical, developmental and appropriate for the late reader. 


\section{CHAPTER II}

\section{REVIEW OF THE IITERATURE}

\section{DEFINITION OF READING READINESS}

Readiness is a composite of several different skills and factors which enable students to read without needless frustration and difficulty. Teachable readiness skills are visual and auditory discrimination and language and conceptual skills. The readiness factors which are more difficult to teach, but can to some extent be nurtured, are environmental background, learning experiences, and maturational level.

Defining the maturational level has created many different opinions as to when a student can and should begin to learn to read. Early research emphasized the importance of delaying beginning reading instruction until a certain maturational level had been reached (Huey, 1908). Morphett and Washburn (1931) suggest the mental age of $6 \frac{1}{2}$ years as the optimum time to begin reading instruction. In its most restricted form, the proponents of a maturational attainment suggest that there is little that can or should be done to alter the course of this maturational process. Environment, and the learning experiences therein, has also been emphasized as a major contributing factor to 
students' preparation for learning to read (Witty, 1947, Sheldon and Carrillo, 1952, Rogers, 1976). This position suggests that reading readiness can be brought about through a predetermined sequence of learning experiences for each individual student.

More recent information indicates that a student's readiness to learn to read involves a combination of maturation and environment (Durkin, 1974, p. 38). It must also take into account the relationship between the student's particular abilities and the kind of learning opportunities made available. There is no magic age or maturational level at which a student becomes "ready to read." A readiness test can identify what the student's abilities are and on that basis appropriate learning opportunities can be provided.

Reading readiness may mean training in particular skills related to, and often including, reading such as hearing and seeing the differences in letters and words, following a sequence of pictures, associating words and pictures, naming letters and so on. Although reading-readiness training precedes formal reading instruction, it should not leave off where independent reading begins. The readiness period of instruction should provide for the integration and practice of the skills which will be utilized in the reading task. This means not only preparing for decoding sound to grapheme relationships, but integrat- 
ing words with meaning to understand and express concepts and experiences. During readiness instruction, much of this training is done verbally, but studies indicate that teaching students to read words and letter forms is more successful than training in non-word forms (Barrett, 1965). Reading readiness should include activities with printed language to develop visual discrimination, left to right progression, and concepts of language which are basic to the task of reading ( $\mathrm{Hall}, 1976$ ).

A readiness period must attempt to improve student adjustment or maturational level as well as provide learning experiences to facilitate the development of the factors and skills directly related to learning to read. Some factors may be brought about by training and experience both at home and at school. These factors are more tangible in their nature than those which come about primarily through the process of maturation. Some factors are only situations which tend to foster reading readiness while others are skills and levels of development brought about by experience and planned programs of instruction. It has been postulated that within the limits of a student's maturational level, observed weaknesses in readiness skills can be strengthened by properly planned and sequenced prereading instruction (Ciymer and Barrett, 1969).

The next step in identifying reading readiness is to define the specific skills and factors which are essential 
to learning how to read.

Reading-Readiness Skills

Soon after birth a child begins to acquire information and skills which are essential for learning to read. Children learn to recognize spoken words and visual objects. They learn to understand what words in our language mean, how to conceptualize and how to reason. All these abilities are directly involved in learning to read.

Auditory Skills. During the early years a student learns to discriminate the sounds of words. Auditory acuity appears to be well developed at five years of age (Robinson, Strickland and Cullinan, 1977). Auditory discrimination of language sounds has long been recognized as a basic process of reading (Rossignol, 1948). The student who has played games involving rhyming words or repeating words with the same initial sound acquires an insight into the sound characteristics of words that will make it easier to learn phonetic instruction in beginning reading (Gates, 1947). With the resurgence of interest in phonics, auditory perception is becoming more important to the reading task. Auditory perception skills include 1) auditory sequencing, 2) auditory memory span, and 3) auditory discrimination. Jansisy and deHirsch (1972) found that imitating a series of sound patterns was related to reading competence. Auditory memory span refers to the duration of attention as well as to the amount of information which can be stored 
and recalled within a particular time span. This is usually tested by repeating numbers or words. Auditory discrimination is the ability to notice separate sounds in spoken words and to identify those sounds. For example, students must be able to identify the " $m$ " sound in mother, most, machine, etc. poor auditory discrimination has been linked with reading failure. Dykstra (1966) reported positive correlations ranging from .30 to .40 . For this reason, nearly all tests of reading readiness include a section on auditory perception. Visual, Visual-Motor Skills. Visual discrimination and visual-motor skills are associated because of the occular muscle coordination necessary to see single as well as groups of shapes and letters. In learning to read, students must be able to fix their eyes upon a letter and move their eyes from left to right across groups of letters. The category of visual-motor skills also refers to the coordination involved in copying letters and words.

Piaget (1956) noted that visual perception is not a fixed mechanism, but is a developing system which becomes increasingly adaptive with age. Children are born farsighted and gradually develop near-point and standard-distance visual acuity with the $20 / 20$ level achieved at about five or six years of age (Robinson, Strickland and Cullinan, 1977). This developmental aspect operates most strongly in the early stages of reading and becomes less important at higher grades when cognitive and linguistic competencies 
become more dominant (Jansky and deHirsch, 1972). Visual perception may not be a skill necessary to teach a late reader, but the importance of visual perception to the reading task make it important to check the adequacy of this skill.

Visual and visual-motor skills include discrimination of letters and words, visual memory, and copying letters and words. Visual discrimination of letters and words has consistently shown greater predictive value in learning to read than discrimination of geometric designs and pictures (Santa, 1975). The minimum requirement of visual discrimination is the ability to match letters (Durrell, 1956). However, Gavel (1958) demonstrated the superiority of letter naming. This requires a higher degree of verbal symbolic functioning than letter matching which demands primarily a visual perceptual response.

Visual memory is an important reading-readiness skill to develop the ability to remember visual patterns of words. Both the length and individual characteristics of words aid in its recognition and Schonell (1961) noted the importance of remembering these visual patterns as a tool of word recognition.

Goins (1958) found that completing the shape of letters was the best single predictor of reading achievement of the 14 possible predictors she studied. Frostig (1966) also 
noted a high correlation between such eye-motor coordination tasks and reading achievement. For this reason, many tests of reading readiness include a section on copying letters. Having students copy letters is one means to train and test students to see likenesses and differences in letters and words.

Language Skills. The language of students is the foundation for reading. Ianguage can both limit and expand students' ability to deal with their surroundings. Oral language is the tool we use to label and explain our environment. Printed language is another tool we teach students so that they can label and explain their experiences. Oral language is well developed when reading instruction begins, unless there are cultural differences or a deprived home environment. Ontogenetically, mastery of spoken language precedes mastery of its graphic forms. If oral language is severely limited, it is difficult to teach reading. The importance of oral language in relation to reading was significantly noted in a study by Loban (1963) in which it was found that students who ranked high in oral language ability at the kindergarten level also ranked high in reading achievement in later years.

The subskills of language development include vocabulary, syntax, and semantics. Vocabulary development is necessary to expand language. Providing interesting models with people, recordings, films, and rhymes can help students 
develop their vocabulary more fully. Pronunciation, still developing in five-year-olds, is only partially aided by maturity and requires experiences which will foster the development of articulation (Robinson, Strickland and Culiinan, 1977). The late reader usually has the advantage of both a richer oral vocabulary and finer pronunciation simply because maturation and experiences have nurtured these abilities. The vocabulary acquired by a student is a very important indicator of general learning ability as well as success in learning to read (Harris, 1975, p. 248).

A knowledge of syntactical (grammatical) structure is an important part of language development. The cloze procedure, used to test reading ability and teach reading comprehension, is largely dependent upon the understanding of syntactic structure. Iinguists have pointed out that unfamiliarity with the standard English used by teachers and in school books may be a major reason why some students are unable to understand that kind of syntactic structure. It has been found that ability to generalize syntactic rules is necessary to verbal expression (Jansky and deHirsch, 1972).

Semantics refers to the meanings and relationships of words. Students who have a limited understanding of relational terms may have difficulty perceiving similarities and differences between words. This is often an item on reading-readiness tests used to assess vocabulary development. Studies have shown that knowledge of word meaning 
and understanding of sentence structure essential for reading comprehension (Jansky and deHirsch, 1972).

Oral language training, which consists of building vocabulary, teaching syntactic rules, and the semantic significance of words, contributes to reading success. The better and wider the background of the student's language, the greater the chance of success in learning to read (Sshonel1, 1961).

Conceptual Skills. Conceptual skills involve the ability to conceive abstract ideas generalized from particular instances. The ability to conceptualize is a cognitive, developmental process. To read the word "apple" means that one is able to imagine conceptually the object, its color. shape, size, its uses, and perhaps prior experiences with apples.

As a result of Piaget's work, it is now widely recognized that cognitive growth proceeds through stages of development. Most students begin to learn to read while in the preoperational stage. Piaget (1956) located the operational stage as being between the ages of ? to $I 1$. During this period, the process of representation is extended from spoken words to printed words that can be read. The preoperational, or intuitive, stage extends from age 4 to $?$ years and is thus named because children at this age make decisions based on intuition rather than logical reasoning which they have not yet developed. Many writers 
believe that a major problem with students not learning to read appears to be the students' cognitive confusion about the reading process (Vernon, 1971, Reid, 1966, Downing, 1969). Reid and Downing interviewed students and found that most of them had vague and inaccurate concepts for such terms as "word," "letter," and "sound," and their ideas of what adults do when they read were faulty. This cognitive confusion may well exist as a manifestation of Piaget's intuitive stage of development.

Students who have difficulty understanding the terms used in reading instruction and the purpose of reading often experience difficulty associating separate phonemes with their relation to graphemes, labeling objects, and using inferential reasoning. These are reading skills which are assimilated through cognitive processes. Conceptual skills require an ability to conceptualize in reading as well as in the development of specific concepts such as letters, sounds, and words. Again the late reader usually has the advantage of a further developed stage of cognitive growth.

There is little doubt that students with a wide and rich background of experiences and a great range of information are better equipped to learn to read (Gates, 1947). Some of the basic concepts which aid students in preparing for reading instruction are understanding of color, shape, size, and number. An understanding of common school experi- 
ences such as weather, clothing, home, food, and family are helpful. Language concepts that deal with function, classification and description help students become familiar with words (Nurss, 1972). Gates found that students who were familiar with words and could associate words with experience and objects were more successful at learning to read than students who had limited experience with words. It should be pointed out that much of the specific concept formation is not required for students to learn in order for them to read. The procedure should, however, center attention on words and reveal clearly how useful it is to be able to read words and communicate their meaning to others. Reasoning Skills. Reasoning skills are closely associated to concept skills in their reliance on cognitive development. The reasoning skills which are taught as part of the reading process are usually associated with higher levels of comprehension such as detecting main idea, details, sequence of events, outcomes, and making inferences. These skilis, however, may first be encountered in a readiness program before actual decoding skills have been learned. Picture reasoning, retelling stories, and completing stories provide a means for students to develop thinking and reasoning skills. There are many subtle techniques involved in examining a picture and getting the main idea from it. Similarly, the ability to listen and understand a story requires students to select and organize information, 
follow events, and perceive story structure. The ability to anticipate what comes next in stories greatly assists students in their reading (Gates, 194?). Retelling and completing stories require both expressive and receptive reasoning. These reasoning skills can be taught through experiences which provide analyzing pictures, listening to stories and telling stories.

\section{Reading-Readiness Factors}

There is a distinction between reading-readiness skills and reading-readiness factors. The skills discussed in the previous section have to do with the physical, verbal, and mental reasoning skills which are necessary to learning to read and are teachable through drills, exercises, and classroom practice. The factors discussed in this section are those variables which affect reading success, but cannot always be significantly changed by classroom instruction. Those factors include fixed factors, environmental background, and maturity. Fixed factors are those which are predetermined by the individual student such as chronological age, sex, mental age, and physical health. Environmental background includes the home environment, social experiences, economic, and educational background of parents. Maturity includes the emotional stability, attention span, and the degree of adjustment to school by the student. The fixed factors cannot be altered by classroom instruction, but environmental and maturational factors can to some 
degree be nurtured by manipulating the classroom environment and activities.

Fixed Factors. Students possess characteristics and factors when they enter school or begin reading instruction. Studies differ in the degree of importance given to any of these factors insofar as they influence the success with which students learn to read. One fixed factor is chronological age. Chronological age is often used as a general indicator for an average student's readiness to begin reading, but it is not a reliable measure of readiness (Spache, 1972). Today educators generally agree that by the time students reach the age of five to seven, their perceptualmotor, cognitive, social, and emotional development will enable them to cope with reading (Jansky and deHirsch, 1972). Piaget agrees that chronological age reflects neurophysiological and cognitive maturation. Durkin (1966) found that some students are ready for printed words long before the age of six. However, IIg and Ames (1965) found some students whose intellectual and chronological age would admit them to first grade are not ready for reading. In terms of the late reader, a more advanced chronological age would increase the likelihood of neurophysiological maturation, and unless poor habits or attitudes had already been learned, the late reader would be more prepared to the extent that chronological age reflects maturation. 
Another fixed factor is the sex of the student. Predictions for success in learning to read are considerably more stable for girls than for boys (Jansky and deHirsch, 1972). In American schools, boys tend to read less well than girls which seems to be a by-product of American culture. That is, boys do not conform to the school demands because they attempt to fit the masculine role that is outlined for them. Girls usually have had more experiences with small muscle activities which contribute to success in school tasks (Spache, 1972). Norma Rogers (1976) also found that girls tend to mature earlier than boys and are more oriented to quiet activities which enhance readiness for reading. There have been a few studies which suggest that poor auditory acuity for high frequency sounds (such as $f, v, p, t, k, s h, t h)$ may retard reading achievement. Smith and Dechant (1976) note a greater incidence of high frequency loss for boys than for girls. According to a functional literacy test conducted by the National Assessment of Educational Progress in 1974-1975, 89\% of 17-year-old females met the literacy criterion, while only $85 \%$ of the 17-year-old males did so. Whatever advantage girls have, they remain slightly ahead of boys throughout the process of learning to read.

Mental age, as measured by an I.Q. test such as the Stanford Binet, is also a fixed factor at any one period of instruction. As mentioned earlier, Morphett and Washburn (1931) had a great impact on reading-readiness training 
because they concluded that a mental age of $6 \frac{1}{2}$ years was the most successful to begin reading instruction. Current research still suggests that there is a marked relationship between mental age and ease of learning to read, indicating that there is a critical mental age below which students will have difficulty learning to read (Rogers, 1976). However, reading disabilities occur at all intellectual levels. There are discrepancies between performance on reading-readiness tests and intelligence evaluation. Educators are therefore no longer so sanguine about the validity of I.Q. as a predictor of reading success (Jansky and deHirsch, 1972). One study by Miller (1971) stated that although a mental age of $6 \frac{1}{2}$ is needed for success in most formal beginning reading programs and a mental age of $7 \frac{1}{2}$ is necessary for success in beginning phonetic analysis, at the beginning stages of reading, prior experiences are more important than is intellectual ability. Spache (1972) concurred, stating that a high mental age alone does not ensure success in reading when other aspects of readiness have not been adequately developed.

There are hazards in using any one scale as the basis for determining reading readiness. Mental age and $I . Q$. have frequently been used as general guidelines for placing students and predicting reading success. Jansky and detirsch caution: "The use of but a single index of reading readiness ignores the fact that the whole child goes to 
school and that such factors as wants, interests and attitudes which have biological foundations are fully as important in determining reading readiness as the traditionally used indexes" (Jansky and deHirsch, 1972).

There may be valuable information for teachers in determining the I.Q. of late readers. It has been observed that some late readers who have I.Q.'s that are average or above average are not making the progress in reading that they should in terms of their mental age. These students then may lack readiness in some other factor or factors which contribute to reading success. It will be useful to identify these factors.

Physical health is a fixed factor which influences students' ability to learn to read. Good physical condition, good diet, rest and school attendance affect students' ability and opportunity to learn reading skills (Rogers, 1976). A student with low general health is likely to be listless, easily fatigued, and have a short attention span (Stott, 1973). Good visual and auditory acuity, motor coordination, and speech are necessary to learn reading skills. Students of any age may be afflicted with physical deficiencies in one or more of these areas. Guszak (1972) stresses the importance of checking physical factors before readiness training.

Environmental And Social Factors. Environmental factors include the home situation, social experiences, 
economic conditions, and educational level of the parents. To the extent that environment can be controlled in the classroom, some of these factors can be manipulated to supplement or improve existing conditions outside the classroom. As early as 1934. Troxel found a relationship between home background and readiness to read. She listed the following factors as having a positive effect on students learning to read: 1) small number in the family, 2) opportunities for travel, 3) richness of play experiences, and 4) extent of reading done in the home. Robinson, Strickland and Cullinan (1977) state that students who see reading in the home tend to be successful in reading. When opportunities such as listening to stories, enjoying pictures and books, and relating speech and auditory vocabularies to concrete objects are present, students mature not only in mechanical aspects of language, but also in using language as a tool for thinking (Spache: 1972). Providing a positive introduction to reading, practice in maintaining attention, and acquiring an interest in written language are background abilities for beginning reading that can be developed in the home (DurreI1, p. 42, 1956).

Social experiences can help develop reading-readiness skills. Students who have had trips to the zoo, belonged to social organizations which make things, perform duties and sell products, travelled or been involved in a variety of social situations, have a broader background of experi- 
ence. This background of experience provides the concepts through which students view their world (Rogers, 1976). The breadth of experience both at home and away from home with parents or other people, enriches concept formation. Socioeconomic status, such as parents' educational attainment, income, and occupation, is useful, but only gross variables (Jansky and deHirsch, 1972). These variables are useful to consider in conjunction with the following notions: 1) students are exposed to distinct patterns of learning long before they start formal education, 2) learning is mediated through the social group and life style of the student, and 3) family members or friends may program a student during the preschool years based on their own training and education (Jansky and deHirsch, 1972). It should be noted that studies disagree as to the relationship between social status of the family and reading achievement. Russell (1948) found that parents' education, occupational level, and economic conditions bear directly on readiness testing he studied. Hillard and Troxel (1937) found that education and intelligence of the parents, the interest of the home in the school, and the cooperation of the home with the school helps prepare students socially and emotionally for the reading task. Bennett (1938), however, concluded that there is no clear evidence that the occupational situation of the family is a significant factor in producing readers. 
While there are no conclusive data on the relationship between low socioeconomic status and reading achievement, there is a relationship between social maladjustment in students themselves and reading retardation (Jmith, 1950). For this reason, promoting growth in social maturity at all grade levels is important.

Maturational And Emotional Factors. Maturity refers to the level of growth reached by a student in terms of intellectual, physical, social, and emotional development. The first three of these factors have been discussed previously. Erickson refers to a stage of development called "responsible participation" in which a child becomes productively task oriented and persevering. These characteristics are necessary to some degree for the student to begin learning to read. Tinker and McCullough (1975) found this type of emotional maturity related to learning to read. Miller (1971) found that students who were curious, emotionally mature, responsible, and able to follow directions were successful in reading. She noted that some students do not want to learn to read because it satisfies a number of their needs such as unwillingness to grow up and accept responsibility, or a desire to punish their parents.

Nost researchers agree that the emotional difficulties of students having problems in reading may be the result, rather than the cause, of their academic failure. The process is somewhat cyclical. A student who is slow to 
learn to read may develop emotional problems as a result of poor self-image and feelings of inferiority at not being able to read. Many studies reveal that reading disability is associated with emotional instability, but others point out that personality maladjustments tend to decrease or disappear as reading success occurs. Schonell (1961) noted that poor readers are less confident, persistent, and selfassertive than good readers.

Students must have the emotional maturity to separate from home, defer gratification, control impulses, and adjust to the school (Jansky and deHirsch, 1972). Prescott (1933, p. 97) says:

To engage successfully in reading, the child must learn to work cooperatively with other children, to follow directions, and to listen to group conversation as well as to participate in it. He must be able to attend rather closely for varying periods of time to the instructional activity. He should be persistent, resourceful and courageous in meeting new or difficult problems, and it is important that he engage in learning situations not with fear or anxiety but with self-confidence and a feeling of security.

These are characteristics which require a fairly high level of emotional maturity.

Instruction can play a major role in the development of emotional stability. Students become part of a social group and that group sets a certain pattern of behavior to which they must conform to feel satisfaction. It is possible for instruction to preserve the positive, dynamic values in emotional expression, at the same time observing con- 
formities (Smith, 1950).

An examination of these reading readiness skills and factors illustrates the many skills and conditions which influence students' ability to learn to read. To the extent that these skills can be taught and factors controlled through classroom instruction, much of what is considered reading readiness becomes tangible, definable and teachable. It is important to remember that reading readiness is a general stage of developmental maturity and preparedness. It involves the student's mental, emotional, social, and physical welfare as well as the specific skills directly related to the reading act. 
CHAPTER III

DESCRIPTION OF THE PROBIEM: THE IMPORTANCE OF READING AND INCIDENCE OF READING DISABILITY

In an interdependent society the importance of reading ability becomes the responsibility of each citizen as well as the teachers and educational system. For a society to function properly, there must be a literate population capable of coping with the advancements of technology. of all the skills taught in school, most Americans would probably agree that the most essential skill is reading if students are to become functioning adults in our society. The importance of reading ability becomes greater as technology advances and occupations tend to require higher levels of education and specialized training. Automation continues to eliminate jobs of unskilled or semi-skilled workers who do not possess the reading skills required for their jobs (Harris, 1975, p. 1). The reading level is becoming more advanced for jobs that were once considered unskilled. For example, Sticht, Caylor, Kern and Fox (1972) determined that the minimum literacy levels for army cook, repairman and armor crewman, and supply clerk were reading grade levels of $7.0,8.0$, and 9.0 respectively. In addition to the obvious occupational and economic benefits of 
reading ability, disabled readers are cut off from cultural activities and the emotional and spiritual fulfillment that can be obtained.

In spite of the fundamental importance of reading in adult life, the common belief among employers and the general public is that every year thousands of American youths are dropping out of or graduating from high school unable to be considered functionally literate. Functional literacy as defined by the National Right To Read Effort means being able to perform tasks necessary to function in American society. There is a likelihood that many reading disabilities go unnoticed in the classroom because many students can read familiar material fairly well, but when they are tested individually using unfamiliar words, disabilities are discovered (Haes, 1972). These disabilities may not be noticed until the upper grades where reading becomes increasingly more difficult. There is also the possibility of psychological problems resulting from reading disability. Ruchlis warns that:

The child who has failed to learn to read in first or second grade and who is not given appropriate training in time, becomes so severely damaged psychologically by the experience that it of ten becomes a major cause of maladjustment sufficiently serious to warrant psychological treatment (Ruchlis, 1973, p. 20).

In consideration of the importance of reading in our society, as well as for the individual, it is worthwhile to examine the statistics on reading disability and pos- 
sible causes of reading failure.

Statistics on Reading Disability

The incidence of reading disability depends on the criterion used as well as the population studied. A comprehensive survey of available evidence of reading disabilities in the United States indicates that about $15 \%$ of school children have reading disabilities (Harris, 1975, p. 14). The National Advisory Committee on Dyslexia and Related Reading Disorders (1969, p. 7) reported:

"Eight million children in America's elementary and secondary schools today will not learn to read adequately. One child in seven is handicapped in his ability to acquire essential reading skills. This phenomenon pervades all segments of our society--black and white, boys and girls, the poor and the affluent.

A nationwide study conducted by the National Assessment of Educational Progress and financed by the National Right To Read Effort in 1974 and 1975 attempted to determine the extent of functional literacy among 17-year-old students. Being functionally literate is defined by Right To Read as "being able to perform tasks necessary to function in American society, such as reading newspapers, instructions and drivers' license tests." The study included only those types of reading material considered to be at the functional literacy level. Over 4,200 students across the country were surveyed in each assessment. Students were to answer at least $75 \%$ of the questions in the assessment correctly to be considered functionally literate. 
Using this as a guide, it was found that about $13 \%$ of 17-year-old students were functionally illiterate. Among female students, $11 \%$ failed to meet literacy standards, while a little less than $15 \%$ of the males did so. Among white 17-year-old students, almost $8 \%$ failed to reach the criterion contrasted with a little less than $42 \%$ of the blacks. Over $21 \%$ of students from the disadvantaged urban areas of our country and $20 \%$ of the students from the Southeast were still functionally illiterate according to the study. A complete table of the results from the NAEP study is found in Appendix A.

Roy H. Forbes, director of National Assessment, added, "although the overall improvement is encouraging, at least one out of ten of those students nearing the end of high school is still not able to do basic, everyday reading tasks" (Forbes, 1977).

\section{Causes Contributing To Reading Failure}

The above statistics are not meant to answer questions about why reading disability and illiteracy occur, but to provide the facts. It is the responsibility of reading teachers to be aware of the facts and have an understanding of some of the causes of reading failure.

The causes can be divided into two groups: developmental and educational. The developmental causes of reading failure are due to inadequate physical, emotional, and mental maturity. The educational causes are due to inadequate 
readiness training and inadequate instruction of reading skills. It is important to consider the cause or causes of a student's reading failure to minimize or correct those causes if possible and to plan an appropriate course of study for that student.

Developmental Causes of Reading Failure. The most common physical causes of reading failure are poor visual and auditory discrimination. visual discrimination requires near-point vision, fine eye muscle control, fusion of the two eyes binocular coordination and depth perception (H. M. Robinson and Huelsman, 1953). The extent to which auditory defects can cause reading difficulties depends on the emphasis given to oral instruction. This is particularly a problem if a phonics method is used exclusively. If a hearing loss is involved, it is better to use a visual or kinesthetic method of instruction.

Other physical problems that may influence reading failure are prolonged illness, malnutrition, which adversely affects brain development, behavior, and insufficient sleep (Harris, 1975, p. 290). Muscular coordination and hand-eye coordination are often poor in slow readers. Endocrine malfunctions are a rare cause of reading failure, but may result if a gland is not functioning properly. Pituitary dysfunction may cause reversal tendencies, poor motor coordination or mental retardation (Miller, 1971). 
It is difficult to determine exactly what relationship emotional maladjustment has on reading failure. Students who fail are usually studied some time after their difficulties have begun which makes it difficult to get accurate information on what emotional problems may have been involved. As mentioned earlier, most often emotional maladjustment and reading problems form a reciprocal relationship in which a slight emotional maladjustment leads to reading problems which later lead to more severe emotional maladjustment (Miller, 1971). Harris (1975, p. 301) lists ten emotional problems that contribute to causing reading disabilities. They are:

1) conscious refusal to learn

2) overt hostility

3) negative conditioning to reading

4) displaced hostility (peer or sibling rivalry)

5) resistance to pressure

6) clinging to dependency

7) quick discouragement

8) success is dangerous

9) absorption in a private world

10) extreme distractibility or restlessness

Many researchers believe that most disabled readers have some degree of emotional maladjustment as the result of their inability to read. Schonell (1961) reported that in a study done with army personnel, non-readers were uncooperative, subservient, and inferior. Some were rebellious, defiant, and difficult to manage. When these men were taught to read, they became more positive toward other people, toward those in authority, and toward their own abilities. The degree to which an emotional problem may 
have caused the initial reading failure is difficult to assess. An emotional problem, however slight, may handicap a student's ability to learn reading skills.

There is a substantial relationship between mental age and ease of learning to read. This is not to say that below a particular mental age, reading is not possible. Most success in teaching reading has been observed when students possess a mental age of six years or above. Durkin (1966), however, found that children could learn to read before entering school, but these children needed more time and patience and tended to be bright. As Gates pointed out in 1936, intelligence is one of the main factors influencing the rate at which a student can learn to read. If instruction is paced more quickly than the student's learning rate, failure will result. Mental age may account for reading failure if neurological, congenital, or brain damage is involved. This may cause reversal tendencies, perceptual difficulties, or a lack of motor coordination necessary to perform reading tasks.

Educational Causes of Reading Failure. Educational causes of reading failure may result from inadequate readiness and/or inadequate or improper reading instruction. There are several erroneous concepts of reading readiness which may account for inadequate readiness training. One of these is the "mysterious appearance" concept which suggests that a student will learn to read when ready and this 
readiness appears suddenly regardless of instruction. Another erroneous concept assigns failure primarily to emotional and personality maladjustment of the student. It is much easier to label students maladjusted than to examine their background abilities, assess which of these abilities is lacking, and then provide experiences to build them. A third erroneous concept is the mental age concept which maintains that unless students have a mental age of six or more, they will be unable to learn reading-readiness skills. Learning to read depends more on visual and auditory perception and other developmental factors than on scores on intelligence tests (Durrell, 1956, p. 25). Each of these erroneous concepts is little more than an excuse for not providing adequate reading-readiness training. Too often students are not provided with appropriate readiness training because it is assumed that they are not "ready." This undermines the purpose of readiness training which is to build readiness.

For late readers, readiness training may mean retraining in some of the earliest pre-reading skills. It is felt by some researchers (Ruchlis, 1973) that the teacher or tutor must go back far enough in the learning sequence to insure that the student will not experience similar failure. This may mean returning to the very earliest reading levels, sometimes even as far back as learning or relearning sounds of letters of the alphabet. It is the first responsibility 
of the teacher to assess the readiness skills of the students and provide activities and experiences to develop the skills that are lacking.

Adequate readiness training before the introduction of any new reading skill is important. The importance of reading readiness is not confined to the pre-reading stage. As students progress through the educational levels from first grade through graduate school, they will continue to meet new fields of thinking related to readings for which their background of experience leaves them unprepared. There is a need for a program of readiness for the thinking side of reading even when the mechanics of reading have been acquired (Harrison, 1936, Part II, p. 4).

Adequate readiness training is especially true for immature and slow-learning students. If pre-reading skills are being taught, a reading-readiness test should be administered to assess whether or not students have acquired the skills that will facilitate their learning to read. If the results are low, reading-readiness activities should be continued. The language experience approach has been found successful with slow-learning students (Miller, 1971). Durrell (1956, p. 25) found that some of the causes of reading failure were in reading-readiness programs. The following are common weaknesses he observed:

I) failure to observe differences in the ability of the students

2) failure to start reading instruction immediately for rapid learners 
3) failure to provide instruction adequate for mastery of reading-readiness skills

4) following an over-complex program with too many nonessential elements

5) attempting to build a sight vocabulary before teaching letters and sounds in words

6) evading responsibility for reading-readiness instruction.

Some of these weaknesses could be avoided if teachers were knowledgeable about reading-readiness skills, assessment, and instruction.

A second major educational cause of reading failure is inadequate or improper instruction. This may result from poor teacher expertise, reliance on basal readers, or using one method only. It is not unusual for teachers to lack an introductory course in reading prior to a teaching assignment which requires them to teach reading. Current research (Durr, 1977) indicates that teachers can assist their students by teaching reading skills in the content area subjects. Consequently, courses in reading are becoming a requirement for teachers of all subjects and grade levels. Poor teacher expertise may have some serious long-range effects on students. Inadequate teaching may result in instruction which is not adjusted to the level and learning rate of the student, failure to provide necessary motivation, and actually teaching poor habits such as word-byword reading, inattention to content, lip movements in silent reading, or ignoring difficult words. Teachers who are unaware of reading skills may fail to teach the early skills on which later skills are based. 
Relying on a basal reading program can have two potential drawbacks. One is that a basal reader assumes that the same scope and sequence should be followed by each student. There may be enrichment activities for fast learners and follow-up exercises for slow learners, but basically the basal reading program prescribes the same method and sequence for all students. The second drawback is the inclusion of unnecessary elements or skills which may not teach reading skills at all. For example, some basal readiness programs include lessons designed to teach students to string colored beads in a particular sequence. There is no evidence to support the conclusion that training in non-verbal sequencing helps prepare students for reading (Santa, 1975).

Using only one method to teach reading has some of the same drawbacks as using a basal reading program exclusively. Again the assumption is made that all students learn the same way. Some researchers believe that the most frequent and consistent cause of reading disabilities is failure in method (Maes, 1972). There are currently four methods of teaching reading that are the most prevalent. They are: 1) the basal reader, 2) the phonics method, 3) individual reading approach, and 4) language experience approach (Chall, 1967). Chall made a detailed analys is of the most prevalent methods to determine which method had the greatest success in teaching students to read. She found 
that "research from 1912-1965 indicated that a coje-emphasis method--i.e., one that views beginning reading as essentially different from mature reading and emphasizes learning of the printed code for the spoken language--produces better results" than a meaning-emphasis or whole word method (Chall, 1965, p. 307). Chall also states that evidence does not endorse any one code-emphasis method over another, however, "insisting on one method for all may complicate things further" (Chall, 1965, p. 309). This belief has stimulated the study of learning modalities which emphasize visual, auditory, and kinesthetic approaches to learning, depending on the learner's particular aptitude. If a student fails to learn to read using conventional visual and auditory training, a kinesthetic or language experience approach may prove helpful. Some students may have a unique way of learning, and using one approach rigidly will needlessly frustrate and handicap those students.

To summarize, it is important to remember that some students who fail to learn to read may be failing because of educational deficits. This may occur during readiness training or reading skill instruction. These students may be developmentally capable of learning to read, but they are not receiving the kind of help and instruction they need to progress. Many teachers are not sufficiently trained to diagnose and pinpoint the cause of the student's difficulty. Even when the teacher is able to diagnose the 
cause of the problem accurately, the problems of selecting appropriate methods and the management problems of providing individual help as needed, make the system difficult to operate. Relying on one method may result in forcing all children to learn the same skills in the same way even though at a different pace, and concentrating on some skills which are not essential to the reading process. Progressing through the levels or magazines of basal readers, for example, can become goals in themselves rather than concentrating on the essential characteristic of reading, which is comprehension. These educational problems can exist at any time during reading instruction. It is the responsibility of the school administration and the teachers to overcome these problems and provide the instruction that will help students acquire the skills they need to learn to read. 
CHAPTER IV

\section{IDEINIFYING READING-READINESS SKILIN}

One of the causes of reading failure mentioned in the previous section is failure to adjust reading-readiness instruction to the individual needs of the student. Before this can be done, one must know what these needs are. The teacher should not assign material that is too difficult or attempt to develop skills for which the students have no background. Students make the most rapid progress when instruction is near their current level of mastery (Farr and Anastasiow, 1969). Information on students' reading readiness needs can be identified from informal and standardized measures. Informal assessment may provide information not available through standardized tests such as behavioral characteristics, medical history, and teacher observation. These assessments may be helpful to supplement other measures. Standardized tests provide a controlled assessment of an individual's current reading-readiness skills. Information from standardized tests may be used to compare students' ability with other students, place students into groups for developing skills which they have not acquired, or identifying specific skills or learning problems that a student may have. 


\section{Why Reading Readiness Tests Are Given}

A readiness test can provide information about a student's preparedness for learning to read. The total score will permit a teacher to rank students from those most ready to read to those least ready, and prepare instruction accordingly. Commercially-prepared tests are used to provide wider prediction and assessment of the students in a class. However, standardized measures should be used with informal measures to obtain the best possible estimate of reading ability (Farr, 1969).

Reading-readiness tests give diagnostic information about specific pre-reading skills and abilities that are measured by the tests. Analyzing the test results reveals weaknesses in some of the measured skills and abilities and can provide the basis for specific corrective instructional practices. Test results may be used to bridge the gap between students coming to school with different backgrounds of experience and having a different body of knowledge and understandings. Where lack of readiness is a product of lack of training, the teacher can increase readiness. Maturation as interpreted by Piaget (1956) is contingent on functioning which in turn is fostered by experience and training. Maturation unfolds in continuous interaction and stimulation (Weimer, 1977). Teachers cannot afford to wait for readiness and maturation to occur, but can provide appropriate training and experiences onse these 
areas are identified. Obviously it is important to examine the test content and be sure that what is being tested is actually a valid reading-readiness skill.

Choosing A Reading-Readiness Test

Reading-readiness tests attempt to measure the particular phases of mental functioning that are most closely related to success in reading. It is important to examine the subtests of a reading-readiness test to determine if the skill being tested is actually related to reading success. Some of the subtests measure acquired information such as knowledge of names of the letters of the alphabet. Different tests have different purposes for which they are designed to measure. For example, some tests are designed primarily to enable grouping of students for reading instruction. Other tests attempt to identify individual skills which for particular students may be unfamiliar. Some tests measure only perceptual or cognitive skills or may be designed primarily to predict success in reading achievement.

In selecting a reading-readiness test, attention should be given to the following factors: 1) validity, 2) reliability, 3) norms, 4) standardization, 5) ease of administration and scoring, 6) time, and 7) objectivity.

Validity is determined by how well the test relates to success in initial reading. This is by far the most important factor. Several aspects of validity should be examined. One is content validity which deals with the 
content of the test or the individual questions in the test. Does the content of a question actualiy represent the skill one wishes to test? Another is concurrent validity which compares the test behavior to current performance. A third is predictive validity which indicates whether the scores students receive can be used to predict how well they will do in the future.

Reliability refers to the degree to which the test gives consistent results. For purposes of individual diagnosis, the reliability coefficient should be at least .90 . The reliability is usually much higher for the total score on a standardized test than is a subtest score, therefore, subtest scores may not prove useful for diagnostic purposes.

The norms identify the population of students on which the test was given and on whom the test was standardized. They should be based on a sufficiently large and representative number of students and should exist for the separate parts as well as the total score. Tests should be selected that have clearly identified norms which most closely match the social, racial and ability levels of the students being tested.

Standardization refers to the establishment of a uniform procedure for the administration of the test. The ease of administration and scoring requires a complete and olear directions manual that is easy to understand and follow. The time a test takes may have important consider- 
ations if parts must be given individually or very restless students are to be tested. Objectivity refers both to the degree to which the bias of the tester and scorer may influence the score and the objectivity of the test items. Some tests include sections which ask the tester or teacher to make subjective judgments about a student's behavior or personality. These items should strive not to be biased against nonstandard-English speaking urban students or rural students who may not be familiar with metropolitan life.

Among the many reading-readiness tests now on the market, the following are recommended by Harris and Sipay (1975, p. 33) as well as several other reading authorities: Gates MacGinitie Readiness Skills Test, Metropolitan Readiness Tests, Clymer-Barrett Prereading Battery, Murphy-Durrell Reading Readiness Analysis, Harrison-Stroud Reading Readiness Profiles and Macmillan Reading Readiness Test. The first four of these tests will be examined in the following section. The last two tests have been omitted because they were recommended the least by other reading authorities, and an examination of their administration manuals provided little information on reliability, validity, and the norms which were used. A table of the four reading-readiness tests examined and the readiness skills included in each test appears in Table II on pages 73 and 74 . 
An Examination of Selected Reading-Readiness Tests

The following tests are examined for the purpose of identifying the skills which have consistently indicated a high correlation with reading achievement. These skills were discussed earlier as reading-readiness skills and included auditory and visual discrimination skills, visualmotor skills, language, concept formation, and reasoning skills. The following tests and their subtests will be examined on the basis of how well they meet the criteria which should be considered in choosing a reading-readiness test. An examination of the individual test sections may prove useful to a teacher who wishes to select a test that will measure those reading-readiness skills.

Gates-MacGinitie Reading Skills Test. The GatesMactinitie Readiness Skills Test is published by College Press, copyright 1968. It is specifically developed to predict success in first-grade reading and is designed to be used at the end of kindergarten or the beginning of grade one. There are eight subtests involved which take a total of 120 minutes. The following is a description of the subtests:

1) Listening Comprehension: measures the student's ability to understand the total thought of a simple story. Twenty stories each with three corresponding pictures. The examiner reads the stories aloud to the students who mark one picture that best answers the question about the story. 
2) Auditory Discrimination: measures the student's skill in distinguishing between two words of similar sound. Twenty-one pairs of pictures. Each pair differs in only one sound. After naming both pictures in a pair, the examiner pronounces the name of one of the pictures again. The student marks the corresponding picture.

3) Visual Discrimination: measures student's ability to distinguish between printed forms of two words. Twenty-four items each consisting of four words--three alike and one different. The student marks the different one.

4) Following Directions: measures the student's skill in following increasingly more coinplex directions. Fourteen items. The examiner reads aloud and the student marks corresponding picture of four.

5) Letter Recognition: measures student's recognition of letters of the alphabet. Eighteen items, with four letters of the alphabet in each item. The examiner names one letter which the student must recognize and mark.

6) Visual-Motor Coordination: measures the student's skill in completing printed letters. Seven letters are models with part of each letter printed in the adjoining column. The student is to complete each letter in the adjoining column following the model.

7) Auditory Blending: provides information about the student's ability to join the parts of a word, presented orally, into a whole word. Fourteen items consist of three pictures each. Examiner pronounces the name of one picture saying it in two or three parts, and the student marks the corresponding picture.

8) Word Recognition: measures the student's ability to recognize whole words when presented in isolation. Twenty-four sets of three words. The examiner reads one word in each set and the student marks that word. This score is not included in the Total Weighted Score. The purpose of this subtest is to determine which students have some reading ability. 
Additional factors of readiness not tested by this test:
a) attention span
b) emotional maturity
c) physical health
d) language background
e) motor coordination
f) amount of prior training and experience
g) kind of expectation and help at home
h) child's attitude toward reading
i) ability to work with others
j) ability to work independentiy.

The subtests include most of the reading-readiness skills mentioned in Chapter II. The listening comprehension subtest requires students to reason and conceptualize the correct answer. Some of these items require students to infer an outcome, understand cause and effect, or remember one of several facts presented. All items ask students to condense the story they hear into one correct visual picture that corresponds with the question they are asked. This involves an interplay of several fairly complex reading skills in addition to an attention span adequate to perform the task.

The Following Directions subtest particularly requires an understanding of language and vocabulary such as same, middle, first, last, between, and farther. The Letter Recognition subtest requires students to integrate auditory recognition with visual recognition of letter names. The auditory blending measures conceptual skills in that students must be able to conceptualize a whole word which is presented in two parts, blend those parts, and mark the appropriate picture. The teacher or examiner is asked to pronounce 
words by dividing them where indicated and pausing one second between each part. Example: R-A-I-N. The artificial nature of this task and low correlation between this task and reading achievement, about .30 , makes the value of this subtest questionable. Subtests $2,3,6$, and 8 cover the auditory, visual, and visual-motor skills involved in reading.

Multiple regression techniques were used to determine the relative weight given to each subtest. Subtests measuring skills and abilities which proved to be the best predictors of reading success were weighted more. Listening Comprehension, Visual-Motor Coordination, and Auditory Blending were given a weight of one. Auditory Discrimination, Visual Discrimination, and Following Directions were given two and Letter Recognition was given a weight of three. This indicates that being able to recognize letters is considered to have the highest correlation with reading achievement.

The content validity of the Gates-MacGinitie Readiness Skills Test is well documented, having been based on two nationwide tryouts involving 2,500 students in grade one. However, the norming population is not well defined. Difficulty and discrimination indices were obtained for all items except the Visual-Motor Coordination subtest. The reliability and validity information for the test is scanty. Individual subtest reliability coefficients are not as 
reliable as a combination of subtest scores, yet only reliabilities for separate subtest scores are given in the technical supplement. The subtests are too short to give accurate validity or reliability information (Dykstra, 1967). No reliability data are given for the whole test.

Metropolitan Readiness Test. The Mletropolitan Readiness Test (MRT), published by Harcourt, Brace, Jovanovich, Inc., has a revised 1976 edition. The purpose of this test is to assess readiness to begin formal school learning. Although the content was developed to provide some measure of pre-reading skills, the manual explains that it is not strictly readiness to read, but readiness to learn that is being assessed. There are two levels of the $1976 \mathrm{IRT}$. Level I is designed for use from beginning through middle kindergarten and Level II for the end of kindergarten and beginning of Grade one. Level I concentrates on the basic pre-reading skills while Level II focuses on the more advanced, high level skills important in beginning reading and mathematics. The total test time is 105 minutes. The following is a description of the subtests:

Level I

1) Auditory Memory: measures the student's immediate recall of a series of words spoken by the teacher. Rationale: early learning, especially reading is a sequential process involving the ability to remember and associate sounds with visual symbols.

2) Rhyming: the ability to hear and discriminate among medial and final sounds in a rhyming context is an important auditory skill. 
3) Letter Recognition: upper and lower case letter recognition when named by the teacher.

4) Visual Matching: matching letter series, words, numerals, and letter-like forms. Rationale: much of early school learning involves the ability to discriminate among visual symbols.

5) School Language and Iistening: basic cognitive concepts and complex grammatical structures are measured. Requires students to integrate and reorganize information, draw inferences, and analyze and evaluate material presented orally. Rationale: important for future development of reading comprehension skills.

6) Quantitative Language: measures concepts such as size, shape, and number-quantity relationships.

7) Copving: an optional test to measure visualmotor coordination by having students copy their first names from a model.

Level I yields scores in two areas. Visual: Letter Recognition and Visual Matching. Language: School Language, Listening, and Quantitative Ianguage. There is no auditory score at Level I since the Auditory Memory and Rhyming tests do not in themselves constitute a sufficiently meaningful, well defined, auditory cluster.

LeveI II

1) Beginning Consonants: measures auditory decoding skill of discriminating among initial sounds of words.

2) Sound-Letter Correspondence: .identifying letters corresponding to specific sounds in words.

3) Visual Matching: a visual-perceptual skill in matching letters, numerals, and letter-like forms. Rationale: much of early school learning involves the ability to discriminate among visual symbols.

4) Finding Patterns: locating formations of letter-groups, words, numerals, or artificial letters when these are embedded in larger 
groupings of similar content. Rationale: finding patterns measures the ability to separate a pattern visually from the context in which it is placed.

5) School Language: basic cognitive concepts and complex grammatical structures are measured using standard American English.

6) Listening: same as Level I, subtest 5.

7) Quantitative Concepts: mathematics

8) Quantitative operations: mathematics

9) Copying: designed to measure visual-motor coordination by copying a sentence model. optional.

Level II yields scores in four areas: 1) auditory-beginning consonants, sound-letter correspondence; 2) visual--visual matching, finding patterns; 3) language--school language, listening; and 4) quantitative--optional.

The subtests in the Auditory and Visual Skill areas concentrate on rather narrow, but important, abilities needed to decode sounds and symbols, while tests in the Ianguage and Quantitative Skill areas emphasize broader language comprehension, reasoning and conceptual abilities that are important in reading. The validity of including visual matching of letter-like forms and locating artificial letters embedded in larger groups can be questioned if the MRT was to be used strictly for reading assessment. These skills may be valid for assessment in mathematics, but are of questionable value for assessment in reading. Level I does not contain a subtest of auditory discrimination, only auditory memory and rhyming. It seems that 
auditory memory and rhyming require some cognitive abilities which are more complex than an auditory discrimination test where students must distinguish if words are the same or different.

Development of the 1976 MRT included two full-scale item tryouts. The first program was conducted with 10,320 students in 40 school districts. Another 10,616 students from 54 school districts participated in the second itemanalysis study. Items suspected of ethnic group bias were dropped, and auditory items in Level II, Form P, were selected to contain only those sounds which are equally familiar to students who speak Spanish, standard American English, or a non-standard dialect.

The norms are thoroughly documented with samples from four different geographic locations and parochial school systems, public school systems with fewer than 300 students, and large-city school systems with enrollments of 100,000 or more. The reliability of the MRT was tested by giving both Form $P$ and Form $Q$ in counterbalanced order with about two weeks in between. The reliability for the subtests range from .73 to .92 with a reliability of .93 for the pre-reading skills composite. A measure of predictive validity was obtained by correlating scores on the MRT with scores on achievement-tests administered in the spring of the same school year, using either the Metropolitan Achievement Test or the Stanford Achievement Test. 
The MRT has very precise directions for administration, and the scoring and interpretation of test results are explicit. The manual warns against using the subtest results as a diagnostic tool, but provides several brochures and resources for teachers to use for skill development in areas where students' scores may indicate weaknesses. The MRT also provides a Practice Booklet to acquaint students with test procedures and familiarize them with the format.

Perhaps the single most useful characteristic of the MRT is the wealth of information on interpreting test scores and specific suggestions for the instructional significance of the various levels of performance. The IURT has, however, been criticized for assessing past achievement rather than predicting future performance.

Clymer-Barrett Prereading Battery. The Clymer-Barrett Prereading Battery (CBPB), published by Personnel Press, Inc., in 1969, is designed for use after the middle of kindergarten or at the beginning of first grade. The manual states that the purpose of the test is to assess the student's levels of accomplishment in certain skills essential to reading. This assessment may then allow teachers to rank their students according to which ones are the most ready to read and which ones are the least ready to read so that a program can be planned and paced accordingly. A second goal stated is to provide teachers with diagnostic informa- 
tion about specific pre-reading skills and abilities measured by the test. This information is said to be available by analyzing the subtest scores and comparing them with one another. There is both a short and long form of the CBPB. The long, diagnostic form takes about 90 minutes, contains six subtests, and yields three diagnostic subscores and a battery total. The short, screening form takes about 30 minutes, contains subtests one and three, and yields a single score useful for screening and group placement. The following is a description of the subtests:

1) Visual Discrimination

a) Recognition of Letters - 35 items, 25 lower case and 10 capital letters. Pupil locates and marks as the teacher reads.

b) Matching Words - 20 items. The student locates and marks the word from four alternative choices.

2) Auditory Discrimination

a) Discrimination of Beginning Sounds in Words 20 items. Requires the student to locate and mark from three alternative choices, the picture whose name begins with the same sound as the name of the stimulus picture. Teacher pronounces names of the pictures.

b) Discrimination of Ending Sounds in Words 20 items. Same as above only with ending sounds. Mostly rhyming words.

3) Visual-Motor Coordination

a) Shape Completion - 20 items measure ability to complete mutilated geometric shape when a completed shape is in view.

b) Copy-A-Dentence - one seven-word sentence. This requires the student to perceive the 
order of letters in words, the groupings of letters which make up words, the sequence of words in a sentence, and to demonstrate perceptual accuracy by copying the sentence in the space provided.

4) Pre-reading Rating Scale

The teacher makes subjective evaluations of the student's behavior in eight areas:

1. facility in oral language

2. concept and vocabulary development

3. skills in critical and creative thinking

4. social skills

5. emotional development

6. attitude toward and interest in reading

7. work habits

8. total

Each has three or four questions which require the teacher to respond on the basis of observing student behavior. The responses are either above average, average, or below average.

The specific tasks required of students taking the CBPB are much more advanced than the other readiness tests examined. This is in part due to the fact that the CBYB was not conceived as a reading readiness test. However, correlation between the $\mathrm{CBPB}$ and readiness tests run in the range of $.55-.80$. Subtests $2 \mathrm{~b}$ and $3 \mathrm{~b}$ correlate the lowest which indicates that these subtests are generally not considered to have high construct validity for reading readiness. An examination of the specific tasks involved in, for example, Ib reveals that whole words must be identified by students. Task $3 b$ requires students to copy an entire sentence. This is a skill which involves more than just visual-motor coordination. An assessment of visualmotor coordination can be made on single words which would 
more likely have meaning to the student. It is not likely that a kindergarten or beginning first-grade student could read and understand a seven-word sentence. Students could no doubt demonstrate a more accurate sample of visual-motor coordination by copying a word that is known to them. Task 3a requires completion of mutilated geometric shapes. This task has been shown to have limited predictive or instructive value to reading readiness.

Some assessment of the student's language development is possible in Task lb, but assessment of conceptualization and reasoning skills are completely lacking. These skills are apparently to be covered by subjective teacher evaluation on the Prereading Rating Scale.

The Directions Manual for the CBPB thoroughly explains the rationale for the test. Some of the tasks were included because of their relation to reading achievement rather than assessment of pre-reading skills. For example, the test authors claim that predictive validity is high because such items as visual discrimination of letters and words is one of the best predictors of early reading achievement. Assessing whether students are capable of distinguishing between letters and words, and are already able to perform this discrimination skill, gives a slightly different emphasis to the test. The test as a whole is predictive of success in learning to read (Farr, 1969), but several of the tasks may be only identifying those students who already possess beginning reading skills. Validity for the use of 
the CBPB as a diagnostic tool is lacking. Individual subtest scores have low reliability, therefore, diagnostic use of this information is not advisable. It would be helpful if various combinations of the subtests were provided to give credence to diagnostic use of these scores.

Reliability information was apparently collected from one test sample involving 5.565 first-grade students in 44 community public schools located throughout the United States. The reliability coefficients for this group are .95 for the long form and .92 for the short form. The data collected for norming the test involved the same 5.565 students and included various school system sizes, and socioeconomic characteristics of the school neighborhood, but the norming population is not described in the technical information section of the manual.

Murphy-Durrel] Reading Readiness Analysis. The Murphy-Durrell Reading Readiness Analysis (MDRRA), published by Harcourt, Brace and World, Inc., has a narrower scope in terms of the skills it tests. The emphasis is on phonic knowledge and letter names. One of the authors explained, "Children who are successful in beginning reading are those who have good backgrounds in phoneme perception. (the ability to identify separate sounds in spoken words) and are familiar with the names of capital and lower-case letters" (Durrell, 1958). The purpose of the test is to enable grouping of students for reading instruction. It may 
also be used as an end-of-the-year prediction of achievement. It is intended for use at the end of kindergarten or the beginning of first grade and takes approximately 100 minutes to administer. The following is a description of the test:

1) Phonemes Test: provides an inventory of the student's ability in identifying sounds in spoken words. Twenty-four items. Students are to mark two pictures which represent words which start or end with a sound dictated by the teacher.

Rationale: The authors believe that the key ability in learning to read is that of identifying separate sounds in spoken words. High intelligence does not assure the ability. Some students learn to speak by "facile imitation" without noticing the positions of teeth, tongue or lips which go with the various sounds. The Phonemes Test measures the most frequent consonant sounds in their initial positions in words and a few in the final position. The phonemes are first taught, then tested to assure successful identification of the sounds and to make clear to students what to do in the test.

2) Letter Names Test: has 52 items which measure the ability to identify capital and lower-case letters named by the teacher.

Rationale: This introductory stage of phonics is important because most letter names contain their sound. When students say the name of a letter, they make all the phonetic adjustment of their speech mechanisms that they will use in reading words containing that letter. Matching letters is not enough.

3) Learning Rate: has 18 items. Measures the number of words a child can recognize one hour after formal instruction.

Rationale: The purpose is to determine the number of words students are able to learn in one day under standard conditions of presentation. If they learn easily, there is no reason 
to delay reading instruction. Part 3 has a low correlation with Part 1 and 2, but together all three parts provide an additional measure of students' readiness to read.

The MDRRA contains an excellent sample of phonetic perception and auditory and visual discrimination. None of the three sections provides an assessment of language development. The learning rate subtest can, to some degree, measure cognitive thinking skills, but this section has a low correlation with Test $I$ and 2 . The test manual contains excellent instructions and directions for administration. Instructional suggestions for students in the highest, middle, and lowest quartile of test results are provided, but the suggestions are very general.

An item analysis was conducted in September, 1963, in three school systems with each system involving 200 or more first-grade students. The subtests and total test showed an average reliability of 990 . Correlation with the stanford Achievement Test--Reading Tests administered in May, 1964, was found to be .64 . The difficulty values of the test items are well balanced. Reliability of the total test is .98 with a standard deviation of 24.4 and a standard error of measurement 3.5. Reliability of the total test is sufficiently high to allow confidence in its stability. Its validity is reflected in a correlation of .80 with the $\mathbb{N R T}$. The predictive validity with the Stanford Achievement Test is .64 with the lowest correlation on the Learning Rate subtest. Standardization of norms was done on entering 
first-grade students from 65 school systems in 12 states. Although the sample is adequate in size, the population is not well described. 


\section{CHAPTER V}

\section{APPIYING THE DATA FROM READING-READINESS TESTS}

It should be emphasized that the use of standardized reading-readiness tests is only one way to determine a student's readiness for reading. There are many informal reading assessments available and indeed, there are readiness factors which cannot be assessed with paper-and-pencil tests. Reading-readiness tests do provide useful information to teachers as predictors of reading achievement and indices for instructional decision. Use of the test results may provide a basis for gathering additional information about individual pupils as well as for the class as a whole. However, all standardized tests are subject to a degree of measurement error. Therefore, other assessments such as classroom behavior and teacher observation should accompany decisions based on test results.

Interpreting the scores of individual students should remain flexible so that personal observation may supplement test information to confirm the results or indicate if additional testing or observation is necessary. Students with high raw scores on the composite skills or total battery may need an informal reading inventory or sight-word list to determine if they are already reading. These are 
the students who can probably begin formal reading instruction immediately. Students with composite scores in the average range may begin to move into activities that are more word, sentence, and story oriented. Some of their subtest scores may indicate further practice in particular readiness skill areas. Students with a low composite score are particularly in need of additional observation and testing. It will be necessary to determine if classroom performance substantiates these findings. A particularly low composite score may indicate a hearing or visual deficiency. Low-scoring students present a particular instructional challenge to the teacher. These students will need instruction in skills which usually develop at an earlier age, such as matching visual and auditory stimuli and social language development. Students in this group should not be placed in a reading program for which they have not developed the underlying skills.

It is extremely important to consider the test results in relation to the method of initial reading instruction that is to be used. Therefore, readiness tests should be selected with specific instructional situations in mind. of the reading-readiness tests examined, all included at least one subtest of visual discrimination. The skills given the next highest priority were auditory discrimination and word meanings and concepts. When the method of reading instruction relies primarily on phonics, the auditory scores 
may provide especially useful information for locating students in need of auditory skill development. However, when the teaching method relies primarily on sight word recognition, the visual scores may provide the most useful information. Reading-readiness tests should assist with the process of formulating a plan for achieving specific instructional objectives. With this possibility in mind, teachers may find readiness tests helpful as diagnostic instruments to provide information about the instructional needs of particular students.

Most reading-readiness tests provide a separate evaluation for visual discrimination, auditory discrimination, knowledge of concepts, visual-motor coordination, listening, and learning rate. The subtests are too short to give a reliable index of each specific readiness skill, but they can provide indications of weaknesses that can be more thoroughly observed by informal tests. For example, if a student scores low on visual discrimination subtests, the teacher may watch for deficiencies in matching pictures, forms, words, and letters during classroom activities. older students often exhibit deficiency in handwriting and spelling.

In general, the readiness subtests can be divided into two areas, decoding skills (auditory and visual skills) and language background skills. These two areas are not highly correlated so that if a student is high on one and 
low on the other, a particular kind of instruction should be planned. For example, if a student is high in language background and low in decoding skills, enriched experiential background may not be necessary. Instead, that student may need more concentrated help in matching words and letters and in listening for rhymes and beginning sounds.

Once the area or areas of weakness are defined, the teacher will want to plan an instructional program that will enable students to learn the skills necessary to succeed in learning to read. The teacher must decide what skills to begin taaching or reteaching, what skills should follow those begun, and what method or combination of methods will be most appropriate. It is to the second point, the sequencing of skills, that the next section is directed.

\section{A Reading-Readiness Skills Sequence}

There have been many debates as to the validity of a skills sequence in reading. While psychologists have known for a considerable length of time that in learning a skill mastery of subordinate units must precede final goal attainment, reading authorities can agree on no such ordered sequence. The problem exists because the task of compiling a learning hierarchy in reading is so complex that a validated reading hierarchy does not exist. Therefore, the reading-readiness skills sequence presented here is intended to be a tentative working list which may be used as a guideline for instructional planning. 
Although a validated reading-skills sequence does not exist, there does exist a number of studies which give evidence to support the theory of a reading-skills sequence. A review of some of these studies will help support the logical appeal for a reading-skills sequence as well as its practical implications for organizing instruction. Basicaliy, a reading-skills sequence, hierarchically arranged, means that each complex reading skill incorporates reading information gained from learning a simpler skill. The skills are arranged so that learning one skill will facilitate learning the next skill in the sequence.

The notion of a hierarchy of skills in reading is not new. In 1899 Bryan and Harter wrote of studies they conducted on acquiring a hierarchy of habits related to telegraphic language. They wrote, "It is not possible to gain freedom in using higher language units until the lower have been so mastered that the attention is not diverted by them. In no case can making the language elements automatic be skipped" (Bryan and Harter, 1899, p. 350).

More recently, Holmes conducted studies formulating a substrata-factor theory of reading. This theory holds that, "Reading is an audio-visual, verbal processing-skill of symbolic reasoning, sustained by the interfacilitations of an intricate hierarchy of substrata factors. . ." (Holmes, 1953, p. 187). Holmes also stated, "The logic and fact of the sequential input is the essential element in teach- 
ing that leads the child himself to develop habits of cortical association. . The content, sequence, and scope of our reading readiness, developmental, and creative reading programs, then, merit our best efforts" (Holmes, 1953. p. 191).

Somewhat later, Ruddell's studies revealed that "language competence and performance appear to move through a developmental sequence during the elementary school years which in some respects parallels the competency model proposed by the transformational grammarian" (Ruddell, 1969, p. 15).

In addition to the empirical evidence that supports a hierarchical sequence of skills in reading, agreement exists concerning what skills are prerequisite. Durkin wrote, "As with any learning, skill in phonic analysis is dependent upon other learnings that are prerequisites" (Durkin, 1974, p. 279). Durkin also believes that, "Students have problems when a less than desirable sequence is followed" (Durkin, 1974, p. 284). She suggests that initial reading instruction should start with letter-sound relationships beginning with single consonants, vowels in short words, vowel generalization rules, and finally multisyllabic words, syllabication, and stress. Durkin stresses the importance of the sequence moving "back and forth between teaching content and teaching its use" (Durkin, 1974, p. 285). Research by Samuels indicates that the subskills of 
reading may be broken down into even smaller units. Samuels wrote, "Even in so simple an associational task as learning a letter name, it appears that breaking the task into subskills facilitates learning" (Samuels, 1976, p. 169). Samuels also states that, "Current research suggests that before one deals with wholes, smaller aspects have to be mastered first. For example, before one can visually process letter clusters as a unit, individual letters have to be utilized" (Samuels, 1976, p. 176). Samuels concludes by saying that even though a validated learning hierarchy in reading does not exist, we do have a reasonably good idea of what the necessary subskills are.

There is also research that indicates a hierarchy of skills exists for reading comprehension as well as the reading acquisition process. A doctoral dissertation by Chapman describes a detailed study conducted to determine whether a hierarchy of reading-comprehension skills could be substantiated. Chapman's hierarchical model included:

1) vocabulary comprehension, 2) sentence comprehension, 3) anaphora comprehension, 4) intersentence comprehension, and 5) inference comprehension. Her conclusion was, "Generally, the planning of instructional curriculum programs in reading should include sequences of skills proceeding from lower order skills to the higher order ones. Specifically, instruction in sentence comprehension should precede that in intersentence comprehension" (Chapman, 1971, p. 184). 
A reading-skills sequence can provide valuable instructional guidelines for a teacher. The complexity of the reading process involves so many variables such as growth and development factors, and language, conceptual, and thinking skills in addition to decoding skills, that sequencing all of these factors would indeed be difficult. However, it may be possible to sequence decoding and somprehension skills in a tentative hierarchical order. Samuels (1966) conducted a kindergarten study of the effect of phonic versus look-say training. A task analysis indisated that knowledge of letter-sounds and the ability to blend these sounds is required for transfer to reading new words. One group received both kinds of training while the others received training in only one method. The group receiving both kinds of training was superior to the groups which did not receive the necessary training. Samuels writes, "The implications of this experiment for the teaching of reading are that task analyses can be most helpful in planning instructional sequences" (Samuels, 1969, p. 35).

For the purpose of aiding the teacher in planning an instructional program, a tentative sequence of reading-readiness skills follows in Table $I$. This readiness skills sequence was developed from many readings on readiness skills, the reading acquisition process, readiness tests, learning hierarchies, as well as my professional experience as a reading teacher. Nost helpful was an outline prepared by Dr. Joanne INurss (1972) for Harcourt, Brace, Jovanovich 
entitled, "Uutline of Farly Learning Cognitive Škills." Also helpful was a study conducted by Samuels in which he concludes, "The most simple task analyses suggest that for the objective of transfer to reading new words, knowledge of letter-sounds, ability to recognize higher-order units and knowledge of their sounds, as well as the ability to blend these sounds into words, are required" (Samuels, 1969, p. 35). The readiness skills are divided into three main groups: decoding, comprehending, and growth and development. The subskills within each group are arranged sequentially, and as much as possible, an attempt was made to sequence the skill areas also. For example, auditory skills precede visual skills because language acquisition develops through speaking and listening prior to the development of visual-motor skills. Quite simply, we learn to listen and speak before we learn to read and write. The growth and development group is included primarily to acknowledge the influence of these factors. The tentative reading-readiness skilis sequence follows in Table I. 


\section{A TENTATIVE READING-READINESS SKILIS SEQUENCE}

Skill

Number Description of Skills

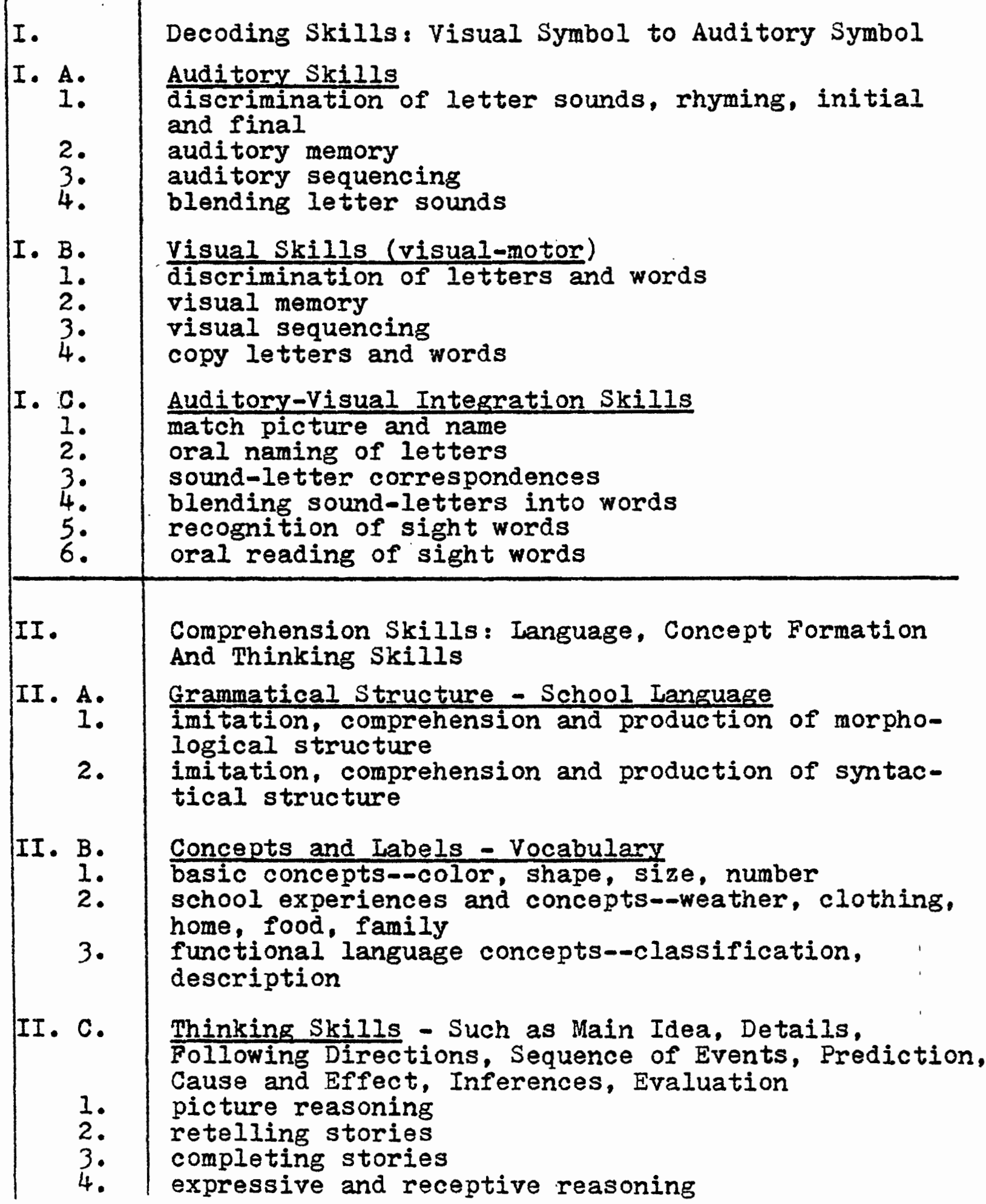




\section{TABLE I (continued)}

Skill

Number Description of Skills

III. Growth and Development

III. A. Physical-Motor

III. B. Sensory-Perceptual

III. C. Social-Emotional

III. D. Language-Conceptual

Using The Skills Sequence For the Late Reader

The major purpose for a skills sequence is to show that by mastering one skill, the next skill follows logically and becomes more easily attainable. Although a validated reading-readiness skills sequence does not exist, this sequence is intended to provide a tentative list of skills that may be used as a guideline for planning instruction. If the skills sequence was arranged in a truly hierarchical order, it would be reasonable to assume that a student having difficulty may need additional instruction or practice with an earlier skill. This is true if the area of weakness identified is in the decoding, comprehending, or growth and development area. Whatever the defined weakness, instruction should be planned to overcome that weakness. At no time should emotionally or physically immature students be kept busy with other activities until they reach a more sophisticated stage of development. Unfortunately, this approach is taken by many teachers who do not know what to do with slow-learning students. These 
students are the ones that become the late readers or in some cases the non-readers. A late reader is defined as a student who does not learn the skill being taught during the initial instruction period when the majority of others receiving the same instruction give evidence of skill mastery. Late readers are those students who score below their age and grade level on a standardized reading test. Using this definition, a late reader may be any grade from kindergarten to high school.

It might be useful to remind the teacher that a late reader is by no means a hopeless case. There are several factors which operate to facilitate success for late readers. For example, older students are often more mature. They may have a longer attention span, a wider range of experience, and a greater vocabulary. They may also have a strong motivation to learn reading skills if they have been confronted dally with the handicap of not knowing how to read or feelings of failure among their peers. These are factors which may provide valuable help when planning an instructional program.

Teachers are familiar with the problem of having to adjust instruction for slow learners. Late readers will also need an adjusted instructional program, often individually tailored to meet their specific reading weakness. The adjustment will depend on the reading weakness identified and the age of the late reader. For instance, if the late readers are first-grade students who are far behind 
the others in the class in remembering letter sounds, those students will need more practice and instruction in auditory memory activities. If the late readers are students in fourth-grade who are having difficulty remembering letter sounds, and tests and observations reveal a correspondingly low reading ability, instruction in auditory memory may mean a longer progression of skill practice to teach and check the skills from auditory memory to the fourth-grade reading skills being taught. In both cases, attention should be given to the materials and method to be used. Obviously, reading materials and methods which are appropriate to the age and interest levels of the students will be the most successful.

Placement on the Sequence of Skills Hierarchy. The reading-readiness skills sequence is meant to assist teachers in planning an instructional program. It is a guideline, providing a tentative list of readiness skills for teachers to consider when planning a program for late readers. The reading-readiness test will help the teacher determine what skills students need to develop. Table II on page 73 identifies which reading-readiness tests include the skills presented in the skills sequence. Identification of these skills will provide a point at which instruction should begin. By referring to the reading-readiness skills sequence, an instrustional program can be organized. For example, a student who is having difficulty with auditory 
blending (skill I A 4 on the skill sequense in Table I) may need to review auditory sequencing (skill I A 3 in Table I).

Table II may be used in two ways. The teacher may administer a reading-readiness test which indicates that a student is low in auditory blending. By referring to the sequence of skills presented in Table I the teacher will find that auditory sequencing precedes auditory blending. Instruction can then focus on building auditory sequencing skills. Another way that Table II may be used is to check informal observations. For example, a teacher may suspect that a student is having difficulty with auditory discrimination. The teacher may refer to Table II and select a reading-readiness test which contains several subtests of auditory discrimination. The test results will identify the area or areas in which the student is weak. The teacher may then refer to Table I to locate the preceding skill and begin instruction at this point. Table II follows on page 73 and 74 .

Activities and reading materials should be selected according to the student's age and ability level. Next a method of instruction should be selected which will be appropriate to the student's age, ability level, and reading weakness.

Selecting A Method. There are many different methods which have proved successful for teaching reading-readiness 


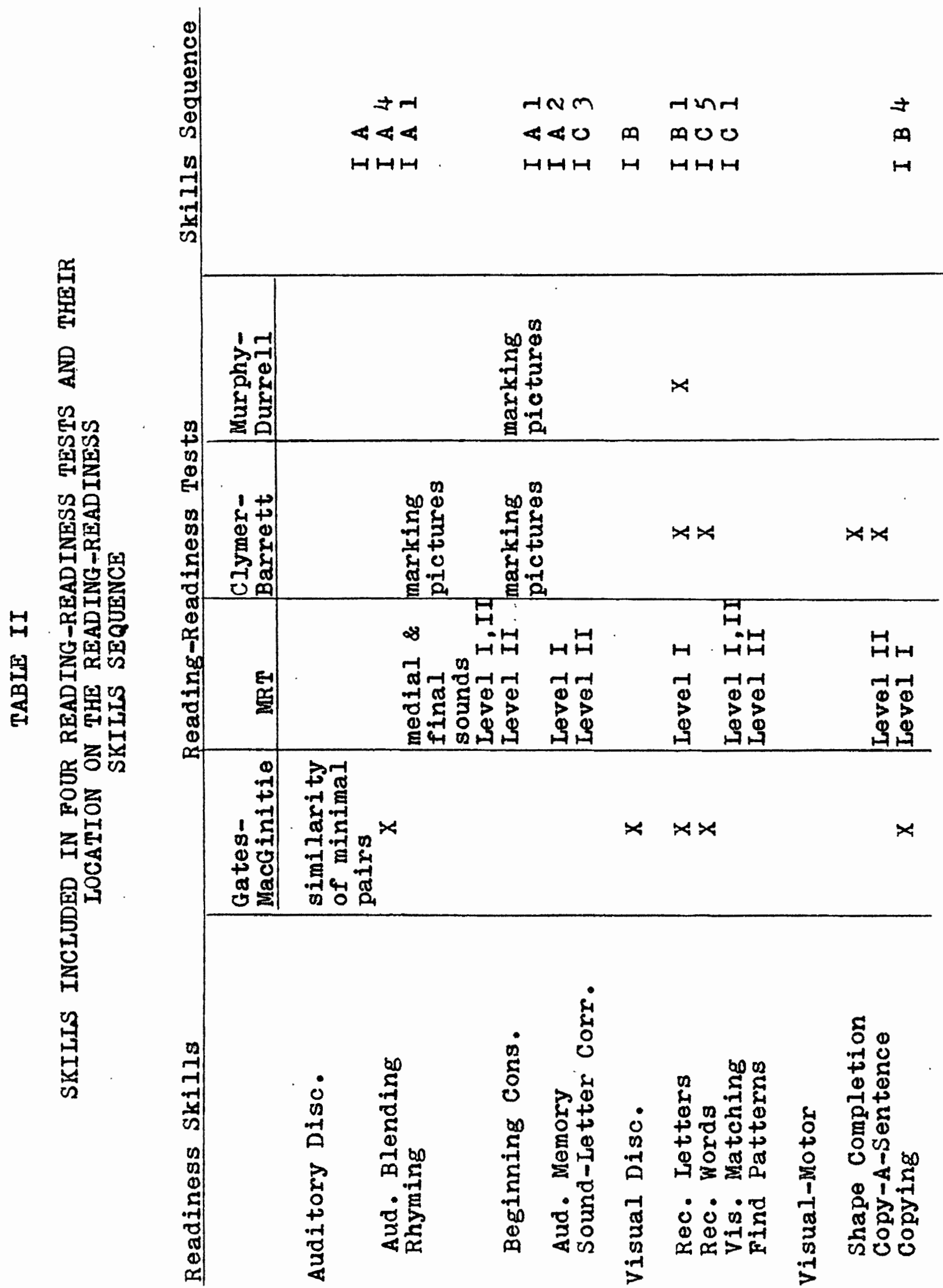



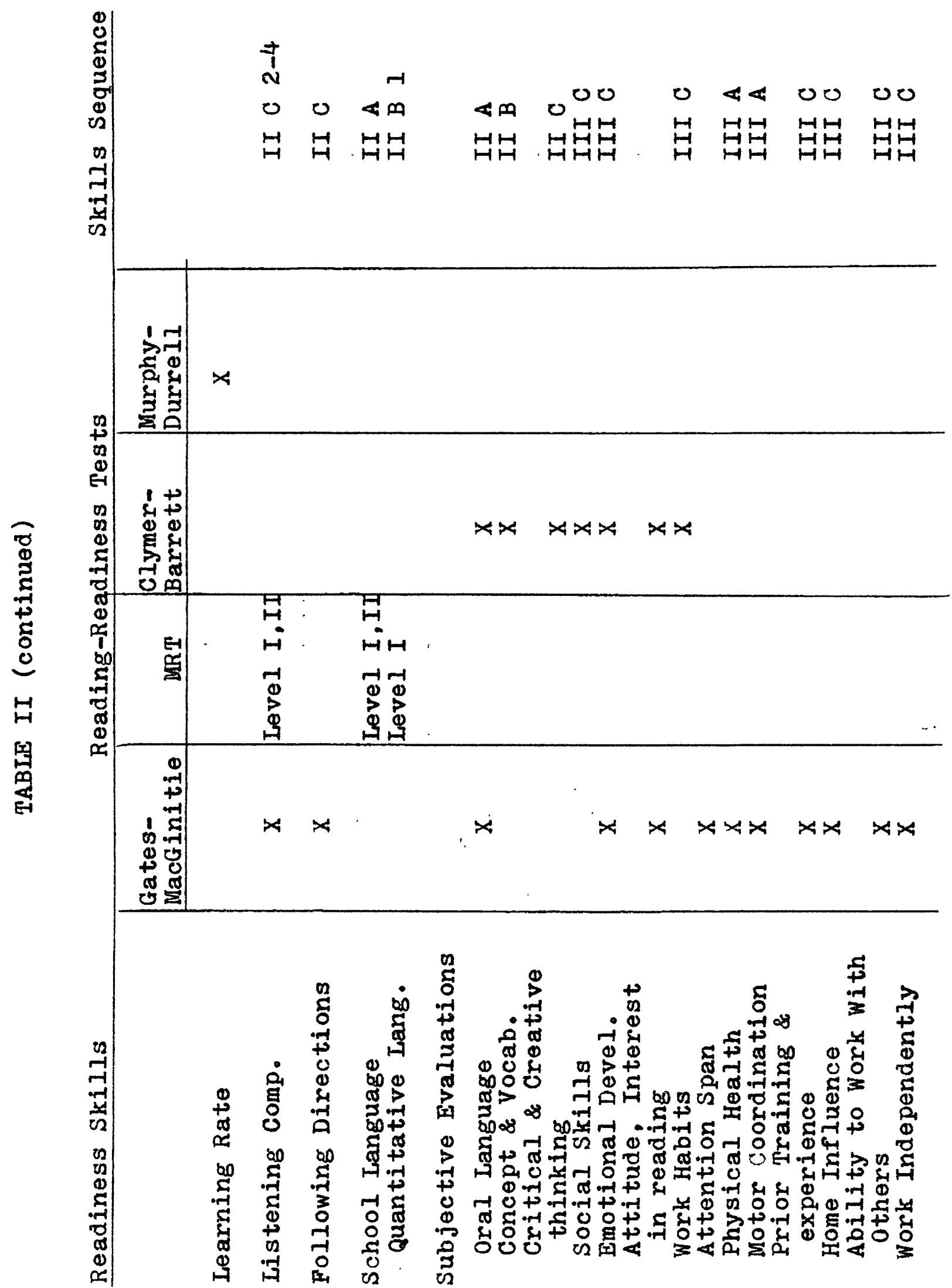
skills. Many researchers believe that it does not matter what method is used. Their belief is that as long as students are continually surrounded with printed language, they will learn to read. There should be some attempt, however, to provide instruction that will enable students to deal with the reading method they will be expected to use in whatever reading program has been adopted by the school or district. For example, if students are required to progress through a basal reading series in which phonics are emphasized, they will need instruction in phonetic analysis as opposed to a whole-word or look-say method. There are several fundamentals which may be useful to consider when selecting a method and planning a program for late readers :

1. Accurate assessment and careful diagnosis is important.

2. The reading material should be sufficiently simple, but suited to the interests, activities, and conversation of the readers' age.

3. Introduce a new approach which will, at least in the initial stages, be different from the type of reading lesson they have usually had.

4. Use as many interrelated forms of learning as possible combining reading, writing, spelling, controlled vocabulary, tracing, and study of word families.

5. Improve attitudes toward reading, provide confidence, encouragement, and feelings of self-worth.

6. Provide tangible proof to students that they are making improvements, such as charts or lists.

7. The program should be based on students' present strengths.

For older late readers, it is helpful for the teacher to get the students ${ }^{\circ}$ help in understanding their reading 
weakness and planning the reading improvement program. Presentation becomes extremely important for the older student, because the content of reading material is often difficult to establish at a primer level. of course, a positive teacher-student relationship will do much to facilitate the reading acquisition process at any age or stage of development. 
CHAPTER VI

CONCLUSIONS

Based on the examination of reading-readiness skills

in this study, the following major conclusions were drawn:

1. Reading readiness is primarily a developmental process which should be considered at all levels of reading instruction.

2. There are several reading-readiness skills and factors which, when acquired, facilitate success in reading.

3. Students who do not acquire reading-readiness skills through their own natural development may require direct instruction in reading-readiness skills, and to a large extent, these skills are teachable.

4. It is possible to assess reading-readiness skills by using a standardized readiness test. These test results combined with teacher observation and informal testing can identify students who need additional readiness instruction.

5. A tentative reading-readiness skills sequence is empirically valid. There are readiness skills and components of other skills, and these skills when acquired, facilitate learning the next skill in the sequence. A teacher may gain useful organizational information by referring to the skills sequence to plan an instructional program for late readers.

\section{Concluding Statement}

This study has sought to examine the skills and factors involved in reading readiness which seem to contribute most to learning how to read. An examination of the literature 
on reading readiness indicated that most of the skills can be taught. In addition, students who lack skill development in any of the readiness skill areas, can be given direct instruction that will increase their ability to learn reading skills. An awareness of the incidence of reading failure and some of the causes for this failure were presented to accent the importance of instructional intervention to help eliminate reading failure.

An examination of selected reading-readiness tests was conducted for the purpose of identifying reading-readiness skill weaknesses which require additional instruction. A tentative reading-readiness skill sequence was developed from an examination of reading-readiness research, readiness tests and the learning acquisition process to assist the teacher in planning an instructional program to meet the needs of the late reader.

Hopefully, this study has made a small contribution to that cumulative knowledge which has sought to gain insight into the components of reading readiness. Nevertheless, much further research will be necessary before effective learning sequences within the reading-readiness skills area can be determined as educators continue to seek better ways to help all students attain reading success. 


\section{A SEIECTED BIBLIOGRAPHY}

Barrett, Thomas C. "Visual Discrimination Tasks as Predictors of First-Grade Reading Achievement." The Reading Teacher. $18: 276-282$, January, 1965.

Barrett, Thomas $C$. "Performance of Selected Prereading Tasks and First-Grade Reading Achievement." Vistas in Reading. Eleventh Annual Convention, IRA, Volume II, Part I:461-464, 1967 .

Barrett, Thomas C. "Predicting Reading Achievement Through Readiness Tests." Measurement and Evaluation of Reading, ed. Roger Farr. Harcourt Brace and world, Inc.. 1970.

Bennett, Chester C. "An Inquiry into the Genesis of Poor Reading." Doctor's Dissertation. New York: Teacher's College, Columbia University, 1938.

Betts, Emmett A. "Factors in Readiness for Reading." Educational Administration and Supervision. 29:199230, April, 1943.

Bond, Guy I., and Eva Bond. Developmental Reading in High School. New York: Macmillan Company, 1941 .

Bond, Guy I., and Wagner, Eva Bond. Teaching the Child to Read. 4th ed. New York: Macmilian, 1966.

Bryan, William I., and Noble Harter. "Studies on Telegraphic Ianguage. The Acquisition of a Hierarchy of Habits." Psychological Review. $6: 345-75,1899$.

Canney, George. "Reading Problems--Prevention Rather Than Cure." Reading Horizons. Volume 18:7-12, Fall, 1977.

Carr, John W.. and Matilda O. Michaels. "Reading Readiness Tests and Grouping of First-Grade Entrants." Elementary English Review. 18:133-38, April, 1941.

Chall, Jeanne S. "Interpretation of the Results of Standardized Reading Tests." Evaluation of Reading, Supplementary Educational Monograph No. 88. University of Chicago Press, 1958.

Chall, Jeanne S., Florence Roxwell, Leonard Alshan, and Mildred Bloomfield. "Language, Visual, Auditory, and Visual-Motor Factors in Beginning Reading: A Preliminary Analysis." A paper presented at the AERA-IRA Meeting, February 11, 1965. 
Chall, Jeanne S. Learning to Read: The Great Debate. New York: McGraw-Hill Book Company, 1967.

Chapman, Carita A. A Test of a Hierarchical Theory of Reading Comprehension. Doctoral Dissertation. University of Chicago Press, Chicago, Illinois, 1971.

Clymer, Theodore and Thomas C. Barrett. Clymer-Barrett Prereading Battery. Directions Manual Form A. Princeton, New Jersey: Personnel Press, Inc., 1969.

Downing, John. "How Children Think About Reading." The Reading Teacher. 23:217-230. December, 1969.

Durkin. Dolores. Children Who Read Early. New York: Teacher's College Press, Columbia University, 1966.

Durkin, Dolores. Teaching Them to Read. 2nd ed. Boston: Allyn and Bacon, Inc., 1974.

Durr, William K. "Reading in the Content Areas." IRA Convention, Miami Beach, Florida. May, 1977.

Durrell, Donald D. Improving Reading Instruction. New York: World Book Company, 1956.

Durrell, Donald D. Murphy-Durrell Reading Readiness Analysis. Directions Manual. Harcourt, Brace and World, 1958.

Dykstra, Robert. "Auditory Discrimination and Beginning Reading Achievement." Reading Research Quarterly. $1: 5-34$, Spring, 1966.

Engelmann, Siegfried. Preventing Failure in the Primary Grades. Chicago, Illinois: Science Research Associates, 1969.

Farr, Roger and Nicholas Anastasiow. Tests of Reading Readiness and Achievement. Newark, Delaware: Reading Aids Series, Institute for Child Study, IRA, 1969.

Forbes, Roy H. "Basic Reading Skills Improve, but. ." NAEP Newsletter. Volume X, February, 1977.

Frostig, Marianne, Welty Lefever, and John R.B. Whittlesey. Developmental Test of Visual Perception. Palo Alto, California: Consulting Psychologists Press, 1966.

Gates, Arthur I., and Guy Bond. "Reading Readiness: A Study of Factors Determining Success and Failure in Beginning Reading." Teacher's College Record. 37:679-685, May, 1936 . 
Gates, Arthur I. "An Experimental Evaluation of Reading Readiness Tests." Elementary School Journal. 39:497508, March, 1939.

Gates, Arthur I., Guy Bond, and David H. Russe11. Methods of Determining Reading Readiness. New York: Bureau of Publications, Teacher's College, Columbia University, 1939.

Gates, Arthur I. The Improvement of Reading: A Program of Diagnostic and Remedial Methods. New York: Macmilian, 3rd edition, 1947 .

Gavel, Sylvia R. "June Reading Achievements of First-Grade Children." Journal of Education. 140:37-43, February, 1958.

Goins, Jean Turner. Visual Perception Abilities and Early Reading Progress. Supplementary EducationaI Monographs, No. 87. Chicago: University of Chicago Press, 1958.

Greene, Frank P. "Reading: Reasons and Readiness." The Tenth and Eleventh Annual Reading Conference held 1968 and 1969. Syracuse, New York: School of Education, Syracuse University, 1970.

Guszak, Frank J. Diagnostic Reading Instruction in the Elementary school. New York: Harper and Row, 1972.

Hall, Maryanne. "Prereading Instruction: Teach for the Task." Reading Teacher. 30:7-9, October, 1976.

Harris, Albert J., and Edward R. Sipay. How to Increase Reading Ability. 6th ed. New York: David Mickay Company, Inc., 1975.

Harrison, Lucile M. Reading Readiness. Boston: Houghton Mifflin Company, 1936.

Heilman, Arthur W. Principles and Practices of Teaching Reading. Columbus, Ohio: Charles E. Merrill Publishing Company, 1967.

Henig, Max S. "Predictive value of a Reading Readiness Test and of Teacher's Forecasts." Elementary School Journal. $50: 41-46$, September, 1949 .

Hilliard, George H., and Eleanor Troxell. "Informational Background as a Factor in Reading Readiness and Progress." Elementary School Journal. 38:255, December, 1937 . 
Holmes, Jack A. "The Substrata-Factor Theory of Reading: Some Experimental Evidence." 1953. In Theoretical Models and Processes of Reading, ed. Harry Singer and Robert B. RuddelI. IRA, Newark, Delaware, 1970.

Huey, Edmund B. The Psychology and Pedagogy of Reading. New York: Macmilian, 1908. Reprinted by MIT Press, Cambridge, Mass.. 1968.

Ilg, Frances I., and Louise Bates Ames. School Readiness. Evanston: Harper and Row, 1965.

Jansky, Jeanette and Katrina deHirsch. Preventing Reading Failure. New York: Harper and Row, 1972.

Kirkland, Eleanor R. "A Piagetian Interpretation of Beginning Reading Instruction." The Reading Teacher. 31:497-503, February, 1978.

Kohl, Herbert. Reading, How To. New York: E. P. Dutton and Company, Inc.. 1973.

Kottmeyer, William. "Readiness for Reading." Elementary English. 24:355-366, October, 1947 .

Loban, Walter. The Language of Elementary School Children. Urbana, Illinois: National Council of Teachers of English, 1963.

MacGinitie, Walter H. Assessment Problems in Reading. IRA, 1973.

Maes, Josephine P. Children Who Can't Read--And How to HeIp Them. New York: Vantage Press Inc., 1972.

Mason, Jana M. "The Acquisition of Reading Skills: A Developmental Stage Processing Model." Reading Improvement. 12:195-202, Winter, 1975.

McHugh, Walter J. "Indices of Success in First-Grade Reading." A paper presented at the AERA-IRA Meeting, February 15, 1962.

Miller, Wilma $\mathrm{H}$. Identifying and Correcting Reading Difficulties in Children. New York: Center for Applied Research in Education Inc., 1971.

Morphett, M.V., and C. Washburne. "When Should Children Begin to Read?" Elementary School Journal. 31:496-503. March, 1931. 
Newman, Harold, ed. Reading Disabilities: Selections on Identification and Treatment. New York: The Odyssey Press, 1969.

Nurss, Joanne R. "Early Childhood Evaluation and Learning Programs: Outline of Early Learning Cognitive Skills." A ditto supplied by Dr. Nurss as part of her presentation at the IRA Conference, February 16, 1972.

Nurss, Joanne R., and Mary E. McGauvran. "Interpretation and Use of Test Results." Metropolitan Readiness Tests. Administration Manual. New York: Harcourt, Brace, Jovanovich, Inc., 1976.

Paradis, Edward and Joseph Peterson. "Readiness Training Implications from Research." Reading Teacher. 28:445448, February, 1975.

Piaget, Jean and $B$. Inhelder. The Growth of Logical Thinking from Childhood to Adolscence. New York: Basic Books, 1956.

Prescott, D.A. "Emotion and the Educative Process." Washington, D.C.: American Council on Education, 1938.

Reid, Jessie F. "Learning to Think About Reading." Educational Research. $9: 56-62,1966$.

Robinson, Helen M., and C.B. Huelsman, Jr. "Visual Efficiency and Progress in Learning to Read." Clinical Studies in Reading, II. Supplementary Educational Monograph NO. 77. Chicago: University of Chicago Press, 1953.

Robinson, Violet B., Dorothy S. Strickland and Bernice Cullinan. "The Child: Ready or Not?" The Kindergarten Child and Reading, ed. Iloyd 0. 0llila. University of Victoria. IRA, Newark, Delaware, 1977.

Rogers, Norma. "What is Reading Readiness?" ERIC/CRIER, IRA Micromonograph, 1976.

Rossignol, Lois Josephone. "The Relationship among Hearing Acuity, Speech Proficiency and Reading Performance in Grades IA, 1B, and 2A." Doctoral Dissertation. New York: Teacher's College, Columbia University, 1948.

Roswell, Florence and Gladys Natchez. Reading Disability, Diagnosis and Treatment. New York: Basic Books, Inc., 1964. 
Ruchlis, Hy. Guidelines to Education of Nonreaders. Brooklyn, New York: Book-Lab, Inc., 1973.

Rupley, William H. "Reading Readiness Research: Implications for Instructional Practices." Reading Teacher. $30: 450-453$, January, 1977 .

Ruddell, Robert $B$. "Language Acquisition and the Reading Process." 1969. In Theoretical Models and Processes of Reading, ed. Harry Singer and Robert B. Ruddell. IRA, Newark, Delaware, 1970.

Russell, David H. "Reading Success and Personality Development." Elementary English. 25:73-82, February, 1948.

Russell, David H., and Etta E. Karp. Reading Aids Through The Grades. Second Revised Edition by Anne Marie Waeser. New York: Teacher's College Press, 1975.

Samuels. S. Jay. "Modes of Word Recognition." 1969. In Theoretical Models and Processes of Reading, ed. Harry Singer and Robert $B$. Ruddell. IRA, Newark, Delaware, 1970 .

Samuels, S. Jay. "Success and Failure in Learning to Read: A Critique of the Research." Reading Research Quarterly. $8: 200-239$, winter, 1973 .

Samuels, S. Jay. "Hierarchical Skills in the Reading Acquisition Process." Aspects of Reading Acquisition. ed. J. T. Guthrie. Baltimore: Johns Hopkins University Press, 1976.

Santa, Carol. "Visual Discrimination: Implications for Reading Readiness and Word Recognition." Paper presented at the Annual Convention. New York: IRA, 1975.

Schone11. Fred J. The Psychology and Teaching of Reading. London: Oliver and Boyd, 1961 .

Sheldon, William D., and Iawrence Carrillo. "Relation of Parents Home, and Certain Developmental Characteristics to Children's Reading Ability." Elementary School Journal. 52:262-270, January, 1952 .

Smith, Nila Banton. "Readiness for Reading and Related Ianguage Arts: A Digest of Current Research." Elementary English. January to May, 1950.

Smith, Nila Banton. Reading Instruction for Today's Children. Englewood Cliffs, New Jersey: Prentice-Hall, 1963. 
Smith, Nila Banton and Emerald V. Dechant. Improving the Teaching of Reading. 2nd edition. Englewood Cliffs, New Jersey: Prentice-Hall, 1963.

Spache, George D. The Teaching of Reading Methods and Results: An overview. Bloomington, Indiana: Phi Delta Kappa Educational Foundation, 1972.

Sticht, Thomas G., John S. Caylor, Richard P. Kern, and Lynn C. Fox. "Project REALISTIC: Determination of Adult Functional Literacy Skill Levels." Reading Research Quarterly, 7:424-465, Spring, 1972 .

Stott, D. H. "Some Less Obvious Cognitive Aspects of Learning to Read." The Reading Teacher. 27:374-383, January, 1973.

Tinker, Miles A., and Constance M. McCullough. Teaching Elementary Reading. Englewood Cliffs, New Jersey, Prentice Hall, 1975.

Troxel, Eleanor. "A Study of the Informal Background of Kindergarten Children as it Affects Reading Readiness." The Educational News Bulletin IV. Michigan, May, 1934.

Vernon, M.D. Reading and its Difficulties: A Psychological Study. Cambridge University Press, Cambridge, Mass., 1971.

Weimer, Wayne and Anne Weimer. Reading Readiness Inventory. Columbus, Ohio: Charles E. Merrill Publishing Company, 1977 .

Wilson, Frank T. "Early Achievement in Reading." Elementary School Journal. 42:609-615, April, 1942.

Witty, Paul. "Reading Retardation in the Secondary School." Journal of Experimental Education. 15:314-317, June, 1947. 


\section{Exhibit D-5}

Percentages of 17-Year-old Students in Each Group who Correctly Answered AT LEAST 90, 75 and 60\% of the MAFL Exercises Correctly. Seventy-Five Percent Is the Minimally Adequate Performance Standard

Exhibit D-5 shows, for each group of 17-year-old students, the percentage who correctly answered at least $90 \%, 75 \%$ and $60 \%$ of the MAFL exercises in 1974 and 1975 (Percentage); the changes from 1974 to 1975 (Chng.); the standard errors of the changes (SECH.); and the probability that each change is due to random error (Prob.). Those changes for which the probability is no greater than 0.050 , i.e., statistically significant, are indicated by an asterisk (*). The difference between $100 \%$ and the percentage of 17-year-old students in any given group that correctly answered at least $75 \%$ of the. MAFL exercises is the group's shortfall from the minimally adequate performance standard.

From the National Assessment of Educational Progress for the Right to Read. 1976 

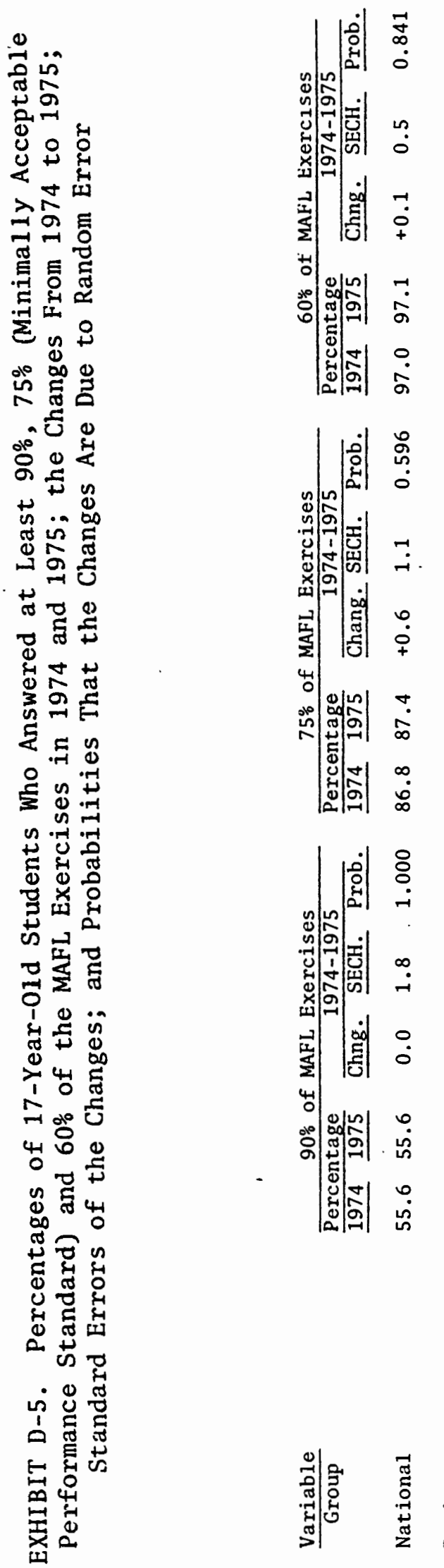

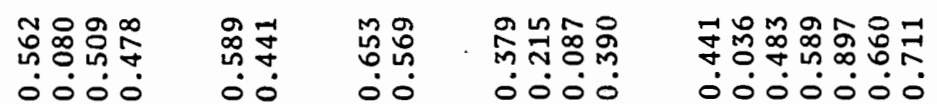

In

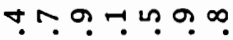

irió

$\rightarrow+e_{m}$

$1+1$
0.00
$0+0$

$\dot{0}+$

m

tonmm

N-0

$m \infty \infty$ ? $\because$ ?

$m \infty$

$+1+$

$\infty \stackrel{*}{n} 0$ or $n+m$

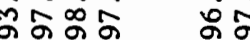

$\dot{\infty} \infty$

on

निं

กฺก

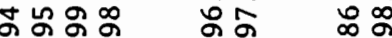

anmo

ナmN寸0 H

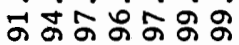

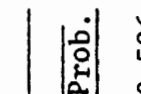

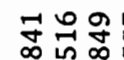

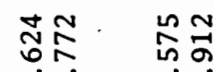

ช่ํㅇㅇㅇ

N

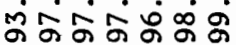

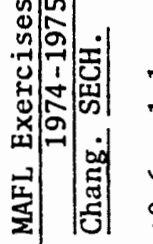

○ं०்

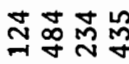

ষั๊

0.00
$\dot{m} \dot{n}$

00

வீं0

வ் $0 \dot{0} 0 \dot{0}$

$\underset{i \rightarrow}{\forall} \quad \stackrel{0}{\dot{0}}$

0 in 0

NaOnNNM

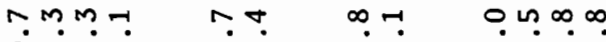

+i்i

$\log 0.00010$

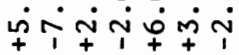

방

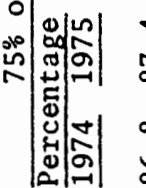

0090

i

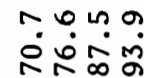

un in in a 00

mก

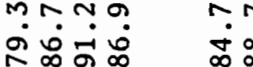

$\leftarrow \infty$

$\dot{\infty} \dot{\infty} \infty \dot{\infty} \dot{\infty} \dot{\infty} \dot{0}$

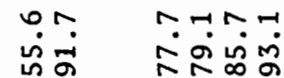

의 n?

लिंم்

$N \infty$

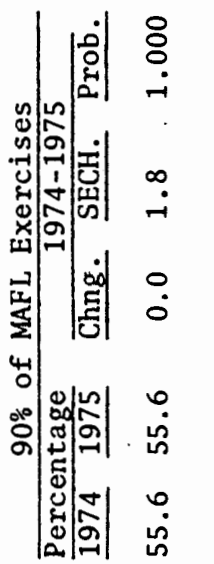

भึ心

g 9

$\stackrel{\infty}{\sim}$

$m \ln$

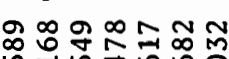

○ं0.

○ं

००

○ं0. :

Nom

N

$\forall \infty$

$\infty \rightarrow N m$

a

कें

mmn

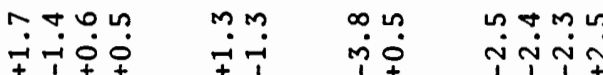

ก.

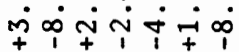

$N \mathrm{~N}$ is

0

$m 0$

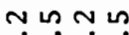

o is on

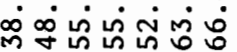

它

กตำ.

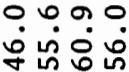

in

룽

लिंकी

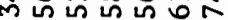
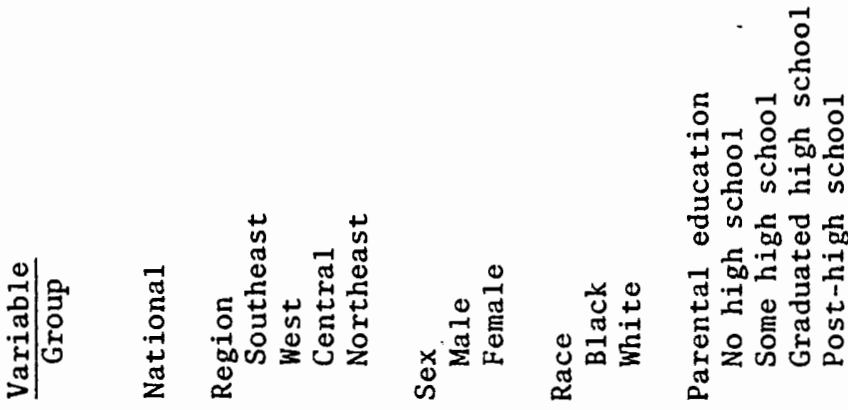

1 क्ष क्ष

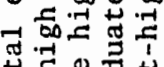

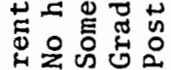

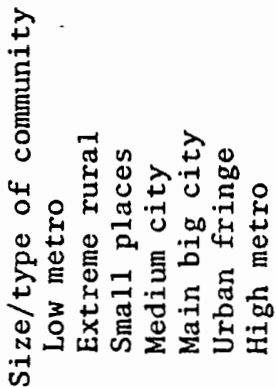




\section{APPENDIX B}

\section{READING-READINESS TESTS}

American School Reading Readiness Test: Revised Edition Available from the Bobbs-Merrill Company.

This test can be given in late kindergarten or beginning first grade and is a group test. It measures vocabulary, discrimination of letter forms, discrimination of words by selection and matching, recognition of geometric forms, following directions and memory of geometric forms. It is available in Form $X$.

\section{Clymer-Barrett Prereading Battery}

Available from Personnel Press, Inc. A Division of Ginn and Company.

This test can be given the last part of kindergarten or first part of first grade as a group test. It contains six paper and pencil tasks and a prereading rating scale. It tests visual and auditory discrimination and visual-motor coordination. There are eight pupil behavior areas for teachers to make subjective evaluations.

Gates-MacGinitie Reading Readiness Test Available from Teachers' College Press, Columbia University This is a group and individual test to be given at the end of kindergarten or beginning first grade. It contains the subtest of listening comprehension, auditory discrimination, visual discrimination, following directions, letter recognition, visual-motor coordination and auditory blending. A word recognition test is included to locate early readers.

Harrison-Stroud Reading Readiness Profiles Available from Houghton Mifflin Company.

This test can be used in late kindergarten or early first grade and contains the subtests of ability to use symbols, visual discrimination, use of context, and auditory discrimination and letter naming.

Lee-Clark Reading Readiness Tests Available from the California Test Bureau.

A test for use in late kindergarten or early first grade and is a group test. It contains the subtests of visual discrimination of letter symbols and word shapes. It also measures a child's knowledge of vocabulary and concepts. 
Iippincott Reading Readiness Test

Available from Lyons and Carnahan Company.

This test can be given the last half of kindergarten

or the first part of first grade. It is a group test and measures each child's knowledge of printed, spoken and written letter forms. The second part of the test contains a readiness checklist.

The Metropolitan Readiness Test

Available from Harcourt, Brace and World. Inc. This group test is designed for use at the late kindergarten or early first-grade level. It measures word meaning, sentence meaning, information, matching, numbers and copying. A supplementary test asks the child to draw a man. (The revised edition has eliminated the final test).

Monroe Reading Aptitude Test

Available from. Houghton Mifflin Company.

This test is partly group administered and partly individually administered. It can be given from beginning grade one and to nonreaders nine years of age. It tests visual discrimination, auditory discrimination, motor control, oral speed and articulation, and language.

Murphy-Durrell Reading Readiness Analysis

Available from Harcourt, Brace, and World, Inc.

This test is a group test and can be given the last part of kindergarten or the first part of first grade. It tests identifying separate sounds in spoken words, identifying capital and lower-case letters pronounced by the examiner, and learning rate by recognizing some sight words an hour after the examiner has taught them.

Stenbach Test of Reading Readiness

Available from Scholastic Testing Service Inc.

This test can be given the last part of kindergarten or the first part of first grade and is a group test. It tests letter identification, word identification, ability to follow directions, and ability to relate words and pictures. 